\title{
Linking Environmental Magnetism to Geochemical Studies and Management of Trace Metals. Examples from Fluvial, Estuarine and Marine Systems
}

\author{
Michael Scoullos ${ }^{1}$, Fotini Botsou ${ }^{1, *}$ and Christina Zeri ${ }^{2}$ \\ 1 Laboratory of Environmental Chemistry and United Nations Educational, Scientific and Cultural \\ Organization (UNESCO) Chair on Management for Sustainable Development in the Mediterranean, \\ Faculty of Chemistry, University of Athens, Panepistimiopolis Zografou, Athens 15784, Greece; \\ E-Mail: scoullos@chem.uoa.gr \\ 2 Hellenic Centre for Marine Research (HCMR), 46.7 km Athens-Sounio Avenue, Anavyssos 10913, \\ Greece; E-Mail: chris@hcmr.gr
}

* Author to whom correspondence should be addressed; E-Mail: fbotsou@chem.uoa.gr; Tel.: +30-210-727-4951; Fax: +30-210-727-4432.

Received: 26 February 2014; in revised form: 17 June 2014 / Accepted: 6 July 2014 / Published: 23 July 2014

\begin{abstract}
Among the diverse research fields and wide range of studies encompassed by environmental magnetism, the present work elaborates on critical aspects of the geochemistry of trace metals that emerged through years of original research in a variety of environmental compartments. This review aims at sharing the insights gained on (a) tracing metal pollution sources; and (b) identifying processes and transport pathways from sources to depositional environments. Case studies on the Elefsis Gulf (Greece) and the Gulf of Lions (France) demonstrate the potential of combined magnetic measurements and chemical analysis to trace pollution signals resulting from land-based sources and atmospheric deposition. Case studies on estuarine environments, namely the Louros, Acheloos, and Asopos Estuaries (Greece), address modes of trace metal behavior under the influence of different hydrological regimes and elucidate in situ processes within the transitional estuarine zone, that define their ultimate fate. As sources, transport pathways, and processes of trace metals are fundamental in environmental management assessments, the involvement of magnetic measurements in the policy cycle could facilitate the development and implementation of appropriate regulatory measures for the integrated management of river basins, coastal, and marine areas.
\end{abstract}


Keywords: trace metals; magnetic measurements; coastal zone; estuaries; integrated management; regulatory framework; DPSIR policy cycle

\section{Introduction}

Several trace metals are biologically important elements useful for biota. However, many of them are recognized as potentially toxic pollutants for soils, waters, and sediments due to the disturbance of their natural, biogeochemical cycles by anthropogenic activities. These include increased releases of industrial effluents, urban wastewater and sludge, fossil fuel combustions, and atmospheric depositions, as well as indirect inputs through alterations of the land uses, resulting in enhanced natural weathering [1-3].

All modern management approaches involving aquatic, marine and other natural ecosystems, such as Integrated Water Resources Management (IWRM), Integrated Coastal Zone Management (ICZM) as well as the Ecosystem Approach (ECAP) and the relative European Union (EU) Directives (e.g., Water Framework Directive WFD 60/2000/EU, Marine strategy Framework Directive MSFD 2008/56/EC, etc.) consider the management of metal flows as critical for the achievement for a good environmental status (GES). Such management is a particularly demanding exercise, involving, among others, assessment of pollution load, identification of sources, comprehension of the transport pathways and the evolution of inputs and impacts on water ways and the depositional environments including estuaries, coastal, and, eventually, offshore marine areas [3-5].

The first application of environmental magnetism in Greece dates back to the late 1970s when one of us (Michael Scoullos) had the privilege of collaborating with Frank Oldfield and Roy Thompson; the authors combined chemical analyses of trace metals in suspended and bottom sediments and magnetic measurements to record the imprints of land-based pollution sources on the coastal marine environment [6]. The work was based on the pioneer idea of linking environmental magnetism to pollution monitoring, that ever since, has found a wide applicability in terrestrial and aquatic systems [7-13]. Despite the fact that there is a vast literature on trace metals in soils and sediments distinguishing among diverse sources (anthropogenic and natural), tracing, mobilization mechanisms, and assessing complex biochemical processes and interactions among the various components of the environment, is still a very important challenge for researchers. To address this challenge various protocols have been designed and applied (e.g., [14] and references therein). Among the various approaches, magnetic measurements constitute one of the most powerful tools in geochemical studies of trace metals [15-19].

Two are the main principles that govern the relationships between magnetic parameters and trace metal concentrations: First, the sources of magnetic particles and trace metals are genetically related. Single emission sites such as coal burning power plants, smelters, cement industries, as well as automobile emissions release into the environment particles that become enriched in trace metals during the production process $[9,13]$. For example $\mathrm{Cu}, \mathrm{Ni}$ and $\mathrm{Cr}$ are common alloying metals that could be found, together with iron magnetic particles, in wastes from metal producing and metal manufacturing processes [20]. Second, specific magnetic components may act as carriers for trace metals. In this case, trace metals that could derive from various sources, are bound to geochemical substrates through adsorption, complexation and co-precipitation processes [9]; these geochemical 
substrates may carry magnetism. In fact, Fe oxides and oxyhydroxides are among the most important, common substrates for binding trace metals $[1,21,22]$. Thus, magnetic measurements are extremely useful for detecting signals associated with the environmental processes [16,17] that evidently define the fate of trace metals during their transport from sources and to sinks, and in some cases also after their deposition in the environment $[1,3,7]$.

The present article elaborates on several case studies of the Laboratory of Environment Chemistry of the University of Athens that combined environmental magnetism and geochemical analysis of trace metals in various environmental compartments. The studies selected for the present review, highlight the advantages gained by the use of magnetic measurements in (a) tracing pollution sources and dispersion patterns in the environment; and (b) assessing the geochemical behavior (processes and transport pathways) of trace metals. Furthermore, this article concludes with some management aspects. We elaborate briefly on how the aforementioned studies could be integrated and inform different faces of policy cycles and modern management approaches, such as Driving Forces-Pressures-StateImpact-Responses, known as the DPSIR approach [23]. The concept of a methodological strategy integrating the scientific component of management in the policy cycle is proposed.

\section{Materials and Methods}

The field and laboratory analytical procedures followed in our trace metals geochemical studies are presented in Figure 1. A detailed description of dissolved and particulate metal sampling, employing commonly used water samplers (e.g., HydroBios, Niskin) and analysis can be found in our earlier publications $[24,25]$ and only a brief description of the analytical protocols for trace metals analysis in sediments and emission (wastes) is given here.

Surface sediments are collected by means of grab samplers and short cores by means of a Mackereth pneumatic corer [26] and Perspex tubes. In the laboratory, the sediment samples are digested in a hot plate with concentrated $\mathrm{HNO}_{3}$ or by strong acids including $\mathrm{HF}$ to obtain the total metal content. The labile, non-lattice held fraction of trace metals are extracted by the single-step $0.5 \mathrm{~N} \mathrm{HCl}$ method of Agemian and Chau [27]. Two Sequential Extraction Schemes (SES), the SES (1) described in Scoullos [28-30] and the SES (2), which is the modified BCR (European Communities Bureau of Reference, now Standards, Measurements and Testing Programme) scheme [31] followed by a total digestion step [32], described in Table 1, provide information on the fractionation of metals among the various geochemical substrates. In sequential extractions the reagent used increases gradually in strength through the steps of the procedure. Thus, the most weakly bound metals to solids are extracted early in the process [11]. Trace metal concentrations are determined by means of Graphite Furnace or Flame Atomic Absorption Spectroscopy.

Determinations of trace metal contents in sediments were performed in the $<63 \mu \mathrm{m}$ fraction in order to minimize grain-size effects [1]. As a second step in most cases, a geochemical normalization to Al was applied in order to reduce residual variance due to compositional (mineralogical) differences within and between the cores [1,33].

Mineral magnetic parameters are briefly presented in Table 2. Much more detailed information on the physical framework for the interpretation of magnetic parameters is given elsewhere (e.g., [15-18,34]). 
Figure 1. Field and laboratory procedures followed in trace metals geochemical studies.

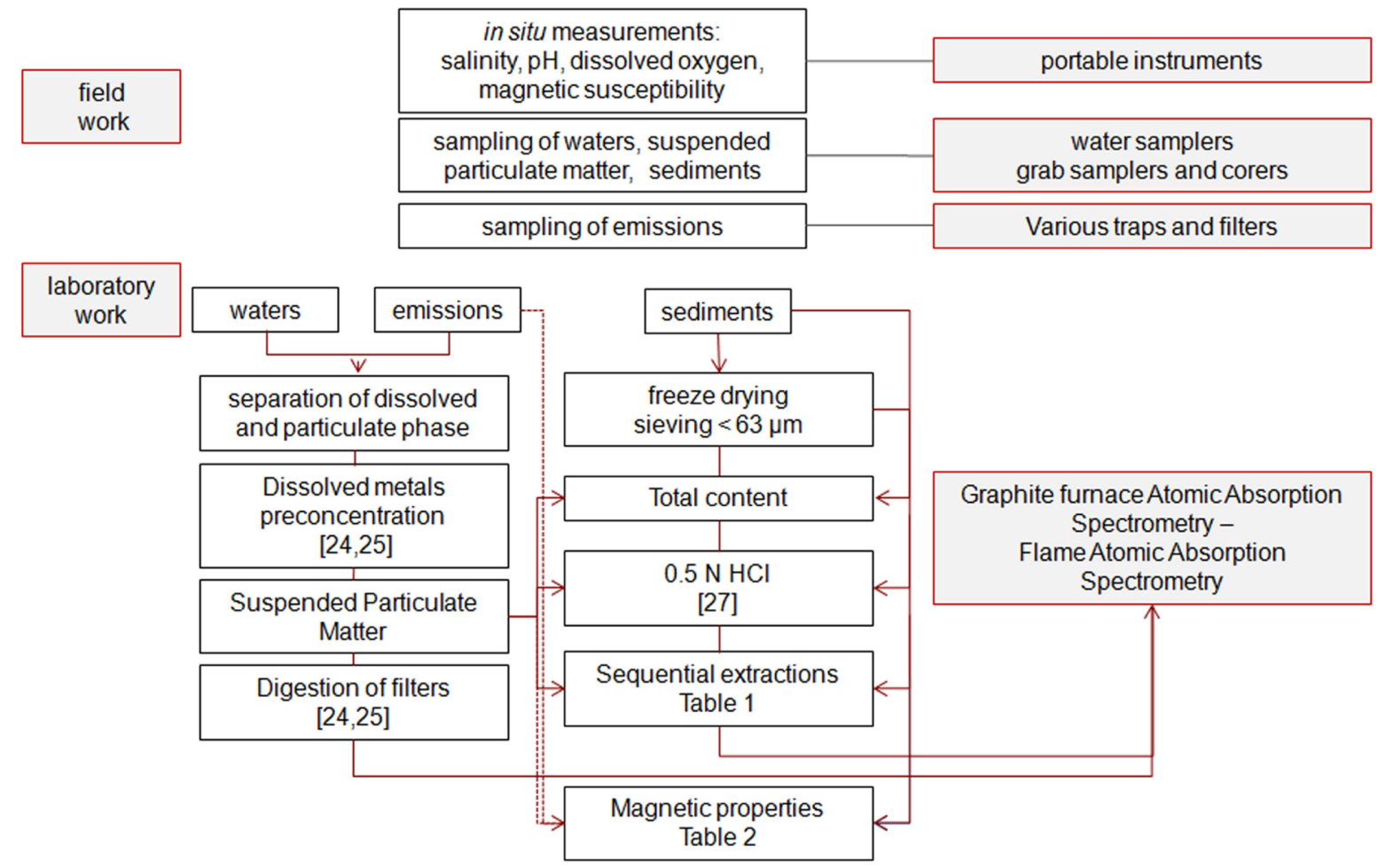

Table 1. Reagents and leachable fractions of metals by Sequential Extraction Schemes.

\begin{tabular}{cccc}
\hline Scheme & Extraction Step $\left(\mathbf{f}_{\mathbf{i}}\right)$ & Reagents & Fraction of Metals \\
\hline \multirow{4}{*}{ SES (1) } & 1 & $\mathrm{MgCl}_{2}$ & Easily exchangeable \\
& 2 & $\mathrm{CH}_{3} \mathrm{COOH}+\mathrm{NH}_{2} \mathrm{OH} \cdot \mathrm{HCl}$ & Non-exchangeable, non-lattice held, inorganic \\
& 3 & $\mathrm{EDTA}$ & Organic \\
& 4 & $\mathrm{HNO}_{3}-\mathrm{HClO}{ }_{4}$ & Pseudo-residual, lattice-held \\
\hline \multirow{4}{*}{ SES (2) } & 1 & $\mathrm{CH}_{3} \mathrm{COOH}$ & Acid-soluble \\
& 2 & $\mathrm{NH}_{2} \mathrm{OH} \cdot \mathrm{HCl}$ & Reducible \\
& 3 & $\mathrm{H}_{2} \mathrm{O}_{2} / \mathrm{CH}_{3} \mathrm{COONH}$ & Oxidizable \\
& 4 & $\mathrm{HNO}_{3}-\mathrm{HF}-\mathrm{HClO}_{4}$ & Residual, lattice-held \\
\hline
\end{tabular}

3. Tracing Pollution Sources, Dispersion Patterns, Evolution of the Impact and Background Levels for Environmental State

\subsection{The Elefsis Gulf}

The first study area where combined chemical analyses and magnetic measurements were applied for tracing pollution signals in the coastal marine environment was the Elefsis Gulf (Figure 2). The gulf receives the impacts from the town of Elefsis and more than 40 industrial plants, including shipyards, oil refineries, chemical industries, as well as iron and steel works. The plant started its operations in 1953 using scrap in electric arc furnaces; in 1963 the first blast furnace, followed by a second one few years later, became operational and the production of cast iron and steel from iron ores (mainly hematite) started. Blast furnaces, as well as a cokery (coking coal ovens), were operational until 1981, and, ever since, the main steel making process consists of electric arc furnaces. 
Table 2. Mineral magnetic parameters.

\begin{tabular}{|c|c|}
\hline Parameter & Description \\
\hline$\chi_{\text {in }}, k$ & $\begin{array}{l}\text { Low-field or initial susceptibility is used as a proxy for the magnetic mineral concentration and is } \\
\text { often equated to the concentration of ferrimagnetic minerals (e.g., magnetite). When the } \\
\text { concentration of ferrimagnetics is low (i.e., }<1 \mu \mathrm{g} / \mathrm{g} \text { ), then magnetic susceptibility will reflect the } \\
\text { concentration of the magnetically weaker canted antiferromagnetic minerals (e.g., hematite, } \\
\text { goethite) and/or non-remanence-carrying paramagnetic minerals (e.g., clay minerals) [34,35]. } \\
\text { It is expressed on a volume-specific basis }\left(k \text { ) or on a mass-specific basis }\left(\chi_{\text {in }}\right) \text {. }\right. \\
\text { In this study initial susceptibility was determined at a frequency of } 0.465 \mathrm{kHz} \text { and is reported both } \\
\text { on a mass specific base }\left(\mathrm{in} \mathrm{m}^{3} \cdot \mathrm{kg}^{-1} \text { ) and on a volume specific base (dimensionless SI units). }\right.\end{array}$ \\
\hline$\chi_{\mathrm{fd}}$ & $\begin{array}{l}\text { Frequency dependent susceptibility. The variation of susceptibility between low and high frequency } \\
\text { (in this study } 0.465 \mathrm{kHz} \text { and } 4.65 \mathrm{kHz}) \text {. The parameter indicates the presence of ultrafine grains } \\
\text { lying in the stable single domain/superparamagnetic boundary }[17,36] \text {. } \\
\text { It is expressed on a volume }\left(k_{\mathrm{fd}}\right) \text { or mass specific base }\left(\chi_{\mathrm{fd}}\right) \text { or as a percentage of the } \chi_{\mathrm{in}}\left(\chi_{\mathrm{fd}} \%\right) \text {. }\end{array}$ \\
\hline ARM & $\begin{array}{l}\text { The Anhysteretic Remanent Magnetization (ARM) is acquired by placing a sample in a decreasing } \\
\text { alternating field from a peak value (here } \mathrm{AF}=100 \mathrm{mT} \text { ) to zero. While the AF field decreases, the } \\
\text { sample is subjected to a direct current bias field with a superimposed small biased direct current } \\
\text { field ( } \mathrm{DC}=0.04 \mathrm{mT} \text { ). ARM is sensitive to the concentration and the grain size of ferrimagnetic } \\
\text { minerals. SD (Single Domain) particles have higher ARM intensities compared to MD (Multi } \\
\text { Domain) particles [18,34]. }\end{array}$ \\
\hline IRM, SIRM & $\begin{array}{l}\text { Isothermal Remanent Magnetization is the magnetization acquired by a sample that is exposed to a } \\
\text { DC magnetic field. The IRM increases with increasing applied field until the response is saturated } \\
\text { and the sample acquires the Saturation IRM (SIRM). A field of } 1 \mathrm{~T} \text { is usually used, although such a } \\
\text { field will not saturate canted antiferromagnetic minerals, which require fields in excess of } 2.5 \mathrm{~T} \text {. } \\
\text { SIRM may reflect the concentration of magnetic minerals, but also responds to grain size variations } \\
\text { and magnetic mineralogy }[16,18] \text {. } \\
\text { It is expressed on a volume-specific base (in A } \cdot \mathrm{m}^{-1} \text { ) or on mass-specific base (in A } \cdot \mathrm{m}^{2} \cdot \mathrm{kg}^{-1} \text { ). } \\
\text { In this study the maximum applied field was } 1 \mathrm{~T} \text { and the imparted IRM is reported as SIRM. IRMs } \\
\text { imparted at lower fields are reported as IRM } \mathrm{IRhere}_{x} x \text { denotes the intensity of the field. }\end{array}$ \\
\hline $\begin{array}{l}\text { IRM }_{-x} / \text { IRM }_{x} \\
\text { IRM }_{-x} / \mathrm{SIRM} \\
\mathrm{S}, \mathrm{B}_{\mathrm{cr}}, \mathrm{HARD} \\
\text { HIRM, SOFT, } \\
\text { Modified } \\
\quad L \text {-ratio }\end{array}$ & 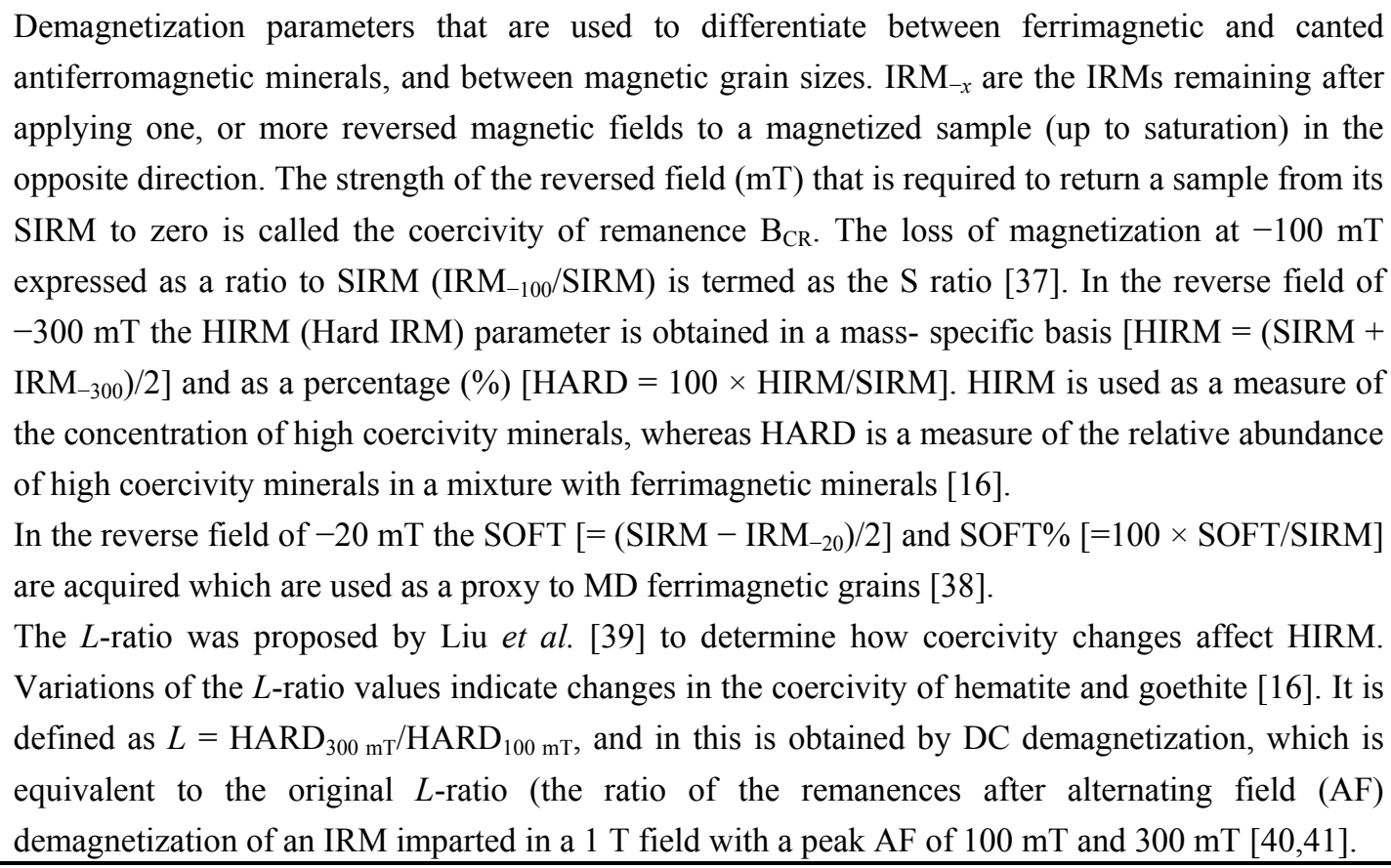 \\
\hline
\end{tabular}


Figure 2. Location of the studied areas.

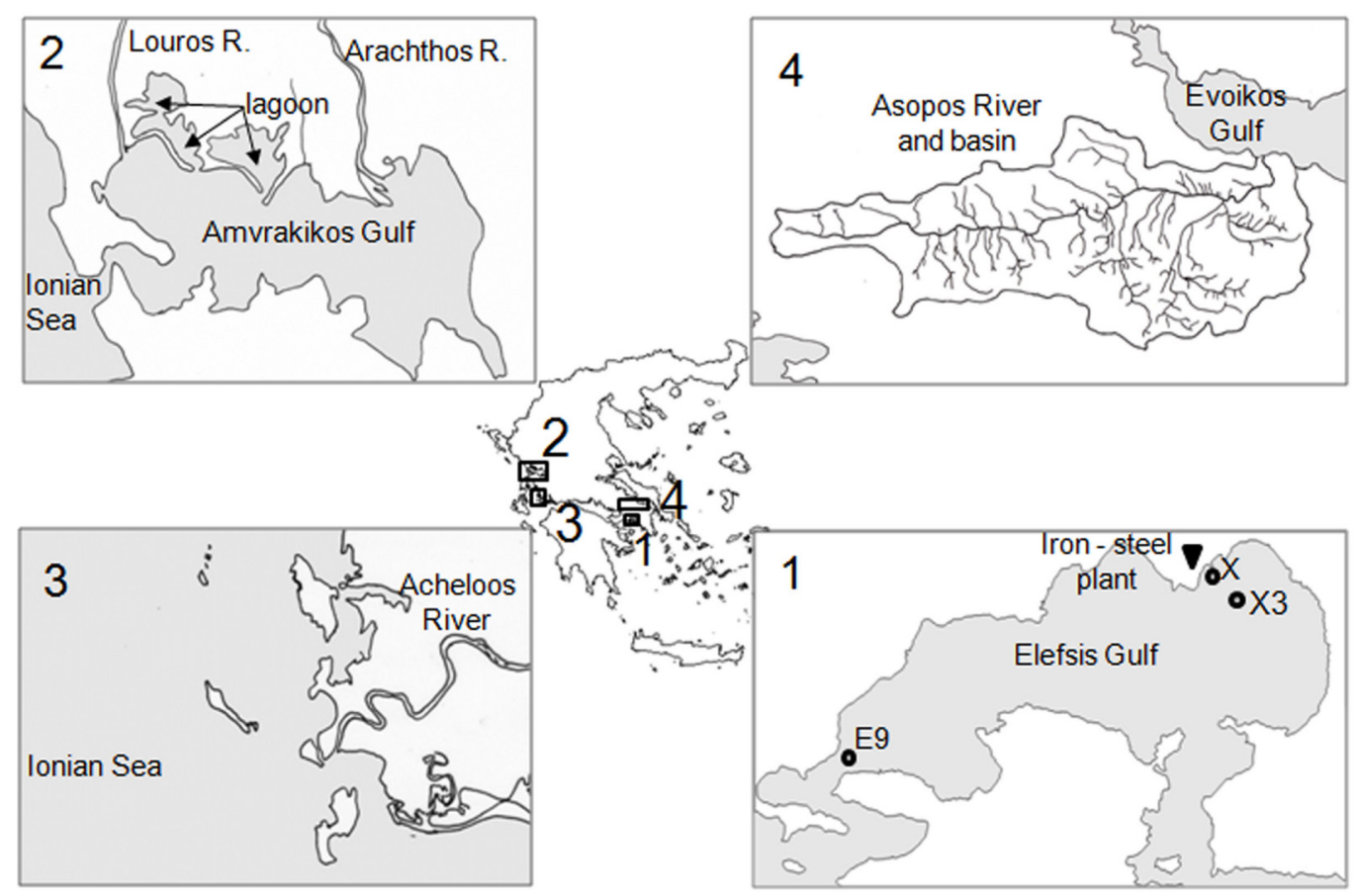

During winter, the water column is well mixed throughout the gulf, whereas during summer, at the deeper western section, the water column is highly stratified and the bottom layers are anoxic $[42,43]$. The water and sediment chemistry of the Elefsis Gulf has been extensively studied by Scoullos [28]. Trace metals were determined in the dissolved and the particulate phase at various depths of the water column on a monthly basis, as well as in surface and cored sediments. Magnetic parameters $\left(\chi_{\text {in, }}\right.$ SIRM (Saturation Isothermal Remanent Magnetization) and coercivities of IRMs (Isothermal Remanent Magnetization)) were determined both in filters holding the suspended particulate matter (SPM) of the water column, and sediment samples.

Particulate Fe concentrations exhibited maxima during August and September, when the waters of the western deepest section of the bay were highly stratified, oxygen-depleted, and the seasonal anoxic regime was fully developed. Thus, on the basis of chemical analysis alone, particulate Fe is thought to be authigenic, originating partly from the redox reactions that occurred in the lower, anoxic part of water column (precipitation of Fe insoluble species, e.g., Fe sulfides), as well as from the dissolved Fe emanating from the anoxic sediments. Part of these dissolved Fe(II) species reach the oxic-anoxic interface few centimeters above the sea bottom and precipitate as Fe oxyhydroxides. However, the origin of Fe was enlightened by means of magnetic measurements on the SPM. The strong, positive correlation between $\mathrm{Fe}$ in the particulate phase and the magnetic properties of the suspended solids, provided evidence that the magnetically active, rich in $\mathrm{Fe}$ oxyhydroxides particles, deriving from the steelmaking process, at the iron and steel making plant located at the NE coast of the bay, constituted a stable component of the particulate Fe population in the studied area [6,42]. Particulate Fe in the form of oxides derives from three major sources: atmospheric emissions, rust on surfaces of steel products that are washed away as impurities during the production process (e.g., rolling mills), as well as wastewater of high concentrations of ionic $\mathrm{Fe}$, which in contact with the alkaline $\mathrm{pH}$ of seawater precipitates as Fe oxyhydroxides. 
Correlation analysis of $\mathrm{Zn}$ versus magnetic susceptibility and SIRM of the suspended solids, particularly during winter, when the contribution of the biogenic and the authigenic component to the suspended solids was minimum [29], indicated that the dispersion patterns of the particles generated by the plant could be "recorded" by magnetic measurements in an easy and cost-effective way. Sequential extractions in sediment samples showed that the major fraction of non lattice-held $\mathrm{Zn}$ was extracted by the acid-reducing reagent (ARR, acetic acid-hydroxylamine hydrochloride; SES (1), Table 1), indicating that a major part of $\mathrm{Zn}$ (on average $24 \%$ of total $\mathrm{Zn}$ content) was bound to carbonates and $\mathrm{Fe} / \mathrm{Mn}$ oxyhydroxides. The correlation of the inorganic fraction of $\mathrm{Zn}$ to magnetic parameters implies that ferrimagnetic Fe oxides formed during combustion either become enriched in $\mathrm{Zn}$ during this process, suggesting a generic relationship, or act as scavengers for $\mathrm{Zn}$, suggesting a common source and transport pathway.

Nevertheless, the assessment of the environmental state of the site and the impact of the operation of the plant on the sediment quality became evident through the combined chemical analysis and magnetic measurements in sediment cores obtained from the coastal marine area at various distances from the plant. Figure 3 presents the vertical distributions of $\chi_{\text {in }}$ in cored sediments obtained $0.3 \mathrm{~km}$ from the artificial lagoon that received the plant's effluents (core X) and $3.2 \mathrm{~km}$ (core X3) offshore. In both cases, $\chi_{\text {in }}$ exhibited maximum values either at the surface sediments or the upper $15-18 \mathrm{~cm}$ of the offshore cores and substantially declined at the underlying sediments. A similar trend was followed by several trace metals $[29,44]$ indicating the rapid accumulation of trace metal pollution linked to the operation of the plant.

Figure 3. Mass specific magnetic susceptibility $\left(\chi_{\text {in }}\right.$ in $\left.10^{-6} \mathrm{~m}^{3} \cdot \mathrm{kg}^{-1}\right)$ and frequency dependent magnetic susceptibility $\left(\chi_{\mathrm{fd}}\right)$ as a percentage of $\chi_{\text {in }}$ in cored sediments sampled in the late 1970s and 2013 from the Elefsis Gulf at distances $0.3 \mathrm{~km}$ from the steel mills (core $\mathrm{C}-\mathrm{X}$ and $\left.\mathrm{C}-\mathrm{X}^{\prime}\right)$ and $3.2 \mathrm{~km}$ (core $\mathrm{C}-3$ ).

late 1970s
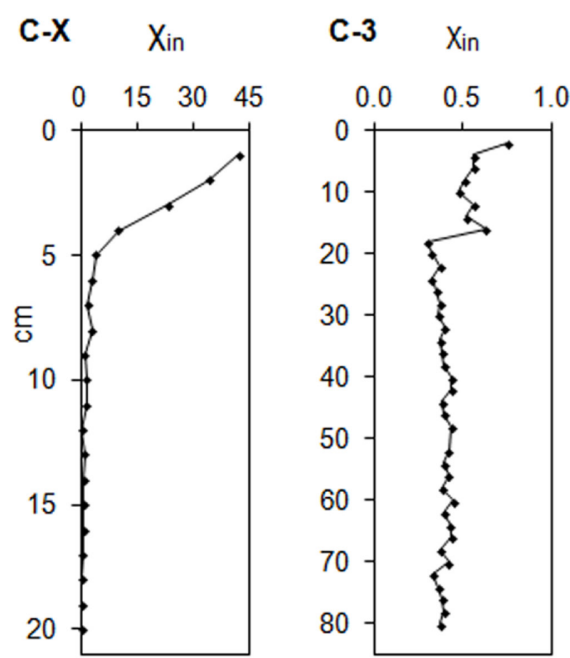
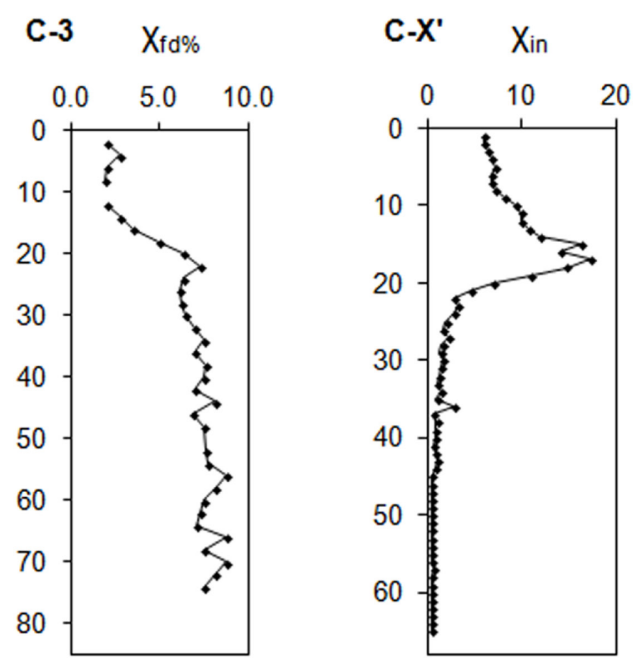

2013

Remagnetization of SIRMs (acquired at $1 \mathrm{~T}$ ) of the surface sediments of core $\mathrm{X}$ at a reverse field of $200 \mathrm{mT}$ and coercive fields $\left(\mathrm{B}_{\mathrm{cr}}\right)$ between 20 and $40 \mathrm{mT}$ indicated the dominant contribution of relatively coarse-grained magnetite to the magnetic assemblage and the low content of antiferromagnetic 
ones [6]. Similar magnetic properties are reported for industrially-emitted dusts and impacted soils and sediments of the surrounding areas [10,12,13,45]. Underlying sediments corresponding to pre-industrial depositions had similar magnetic mineralogy with the surface ones $[6,17]$. However, the vertical distributions of $\chi_{\mathrm{fd}} \%$ clearly illustrated that the sharp increase of $\chi_{\mathrm{in}}$, recording the onset of industrial activity, was accompanied by a decline of $\chi_{\mathrm{fd} \%}$, whereas at the pre-industrial depositions, increased values of $\chi_{\mathrm{fd}} \%$ were determined (Figure 3 ; [46]). As $\chi_{\mathrm{fd} \%}$ is sensitive to natural soil forming processes [8,47-50], these findings corroborated to the dominance of a secondary soil-derived magnetic component in the lower part of the core, and industry-derived component in the upper part.

Thus, it became clear that magnetic measurements alone could demonstrate changes in deposited matter leading to the deterioration of the sediment quality by industrial emissions, as well as to trace the level of contamination and the size of the directly impacted area.

During the first decade of the 2000s the industry has adopted Best Available Techniques (BAT). The operation of technologically advanced production facilities has resulted in a significant reduction of pollution, including in solid waste, water discharge and atmospheric emission. A 35-year-after revisit at the site took place in summer of 2013 in order to explore sediments quality after the application of the pollution reduction technologies. Sediment cores were obtained from the close vicinity of the plant and similar locations of our original research in the area. Preliminary results [51] of magnetic susceptibility, $\chi_{\mathrm{in}}$, and $\chi_{\mathrm{fd} \%}$ in core $\mathrm{X}^{\prime}$ (obtained from the same location as core $\mathrm{X}$ ) are presented in Figure 3. The peak emissions previously recorded at the surface sediments of core $\mathrm{X}$ in the late 1970s, now appear in the 12-20 cm sediment interval. This depth is roughly consistent with the sedimentation rate of $0.5 \mathrm{~cm} \cdot \mathrm{yr}^{-1}$ proposed by Scoullos and Oldfield [44]. Sediments below $36 \mathrm{~cm}$ carry a weak magnetism and at the same time exhibit $\chi_{\mathrm{fd} \%}$ values indicative of pedogenesis processes [8,47]. Obviously, this part of the core represents the pre-industrial local background. The recent sediments of the upper $7 \mathrm{~cm}$ of the core, exhibit $\chi_{\text {in }}$ values up to 2.5 times lower than in the peak discharges in the late 1970s, and evidence the considerable reduction of pollution due to the operation of technologically advanced productions facilities.

The reduction of pollution is attributed, among others, to the installations of state-of-the-art rolling mills and ceasing of effluent discharges through the artificial lagoon into the marine environment, as well as in upgrading the efficiency of filter bags. Filter bags are a dust control equipment used to purify the exhausts of the steelmaking process. Because of the continuous exposure to high temperatures, large amounts of fly ash and dusts, enriched in major elements and trace metals, adhere to the surfaces of, as well as, the vacated spaces between, the filter bags [52].

Strzyszcz and co-workers [12] studied the magnetic properties of dust samples collected from a blast furnace of iron works in Poland; The dusts had high magnetic susceptibilities ranging from $5.9 \times 10^{-6}$ to $6.4 \times 10^{-6} \mathrm{~m}^{3} \cdot \mathrm{kg}^{-1}$ and a soft magnetic behavior, reaching saturation in a field of $300 \mathrm{mT}$, as well as low coercivity $(25 \mathrm{mT})$, low S-values $(-0.72)$ and low $\chi_{\mathrm{fd} \%}(<1.44 \%)$, indicating the predominance of single to multidomain grains of magnetite.

Dust samples obtained from waste filter bags and the sludge from the rolling mills was measured for $\chi_{\text {in }}$ and $\chi_{\mathrm{fd} \%}$ values: Mass specific susceptibility of the dust samples was $53.26 \times 10^{-6} \mathrm{~m}^{3} \cdot \mathrm{kg}^{-1}[51]$ indicating that a significant amount of magnetic minerals is trapped into the filter bag, thus not released into the ambient air. Maximum susceptibilities of blast furnace dust can exceed $450 \times 10^{-6} \mathrm{~m}^{3} \mathrm{~kg}^{-1}$, due to the presence of magnetite at concentrations $>30 \%$ [45]. Magnetic susceptibility of the sludge 
samples of the rolling mills was $98.86 \times 10^{-6} \mathrm{~m}^{3} \cdot \mathrm{kg}^{-1}$ [51]. By proper management of sludge, as well as by recycling of water used for the removal of impurities on roll scales, a significant amount of magnetic minerals are no longer released into the marine environment through overflows of the artificial effluents lagoon. Finally, frequency dependent susceptibility in waste samples as a percentage of $\chi_{\text {in }}$ was below $0.5 \%$, confirming the finding of other authors that superparamagnetic grains are not present in industrially derived particles $[8,49,53]$.

Another application of combined magnetic measurements and trace metals analysis concerned the preliminary determination of the background trace metal levels. It is known that this is an important challenge, in particular for heavily impacted from anthropogenic activities areas. This could be approached by analyzing pristine parts of the system in question. However, this might be particularly difficult or impossible if trace metals are transported through the atmosphere, as is the case for lead [54]. In this case, background levels may be obtained by considering unaffected depths of the sediment core. To identify these depths a detailed chronology is usually required $[1,55]$. In the absence of such chronology, magnetic measurements in combination with knowledge of local conditions may allow the rapid identification of unaffected depths and determination, at least preliminary, of background levels. Indeed, Scoullos [28,30] observing that the cores/sandy texture and magnetic properties of the surface sediments at the western strait linking the Gulf of Elefsis to the rest of the Saronikos Gulf (station E9; Figure 1), were lower or identical to those determined at the bottom of all other cores of the area, confirmed the information about recent dredging of the upper 1.0-1.5 $\mathrm{m}$ of sediments of the site. Determination of the total $\mathrm{Pb}$ levels of this sediment allowed the suggestion of the value of $10 \mathrm{mg} / \mathrm{kg}$ as background, pre-industrial and geological level.

\subsection{The Gulf of Lions}

The magnetic signature of shelf, slope and offshore sediments of the Gulf of Lions and the NW Mediterranean Sea (Figure 4) were studied during 1987-1991 in the framework of the European project EROS-2000. The purpose of the study was to test the capabilities of the magnetic methodology in tracing the dispersion of contaminants in the marine environment. Previous works [53,56] have shown that particles originating from fossil fuel combustion exhibit strong ferrimagnetic behavior and correspond to coarse magnetic grains. Our task was to decipher their presence in marine sediments [57].

Figure 5 shows the spatial distribution of the magnetic parameters measured in a thin surface layer $(0-0.5 \mathrm{~cm})$ of the sediments of the Gulf of Lions (shown in Figure $4 \mathrm{a})$. The parameters corresponding to the magnetic minerals present, SIRM and $\chi_{\text {in }}$, clearly showed that on the shelf areas with depths $\leq 100 \mathrm{~m}$, not strongly ferrimagnetic materials were deposited. Along the steep slope and canyons (200 to $<2000 \mathrm{~m}$ ) of the Gulf of Lions an east-west gradient was formed with a decreasing abundance of ferrimagnetic materials towards the west.

The distribution of ARM indicated that finer single domain ferrimagnetic grains were deposited at the western shelf and slopes, while the SOFT\% component revealed that close to the Rhone River mouth and along the eastern slopes and canyons, coarse multi-domain ferrimagnetic grains were present. In addition, the increased values of $\chi_{\mathrm{fd} \%}(11 \%-17 \%)$ recorded in front of the river mouth and up to a distance of $\sim 40 \mathrm{~km}$ at $200 \mathrm{~m}$ depth, pointed to the input of soil formed particles originating from the catchment (Figure 5c). The picture obtained from the magnetic parameters implied that at the 
shelf area there was high accumulation of coarse grains, not strongly ferrimagnetic, apparently of riverine and terrestrial origin. This was further supported by the relatively low values of the magnetic parameters $\left(13.4<\chi_{\text {in }}<18.810^{-8} \mathrm{~m}^{3} \cdot \mathrm{kg}^{-1}, 21.2<\mathrm{ARM}<52.8 \mu \mathrm{A} \cdot \mathrm{m}^{2} \cdot \mathrm{kg}^{-1}\right)$ measured on five surface sediments collected from the Rhône Estuary, which fell within the range of values of the near-shore sediments. Later works on particle fluxes and transport processes using sediment traps [58-60] have shown that sediments supplied by the Rhône River are resuspended from the shelf during storm events and are transported through submarine canyons towards the deeper parts of the gulf. Sediment transport takes place during storm-induced downwelling of water masses and cold dense water cascading (a current driven solely by seawater density differences). These processes are more intense in the western submarine canyons of the Gulf of Lions, as shown from the fluxes of settling particles, which are up to two orders of magnitude higher in the western than in the eastern canyons [59]. The distribution of the magnetic parameters SIRM and $\chi_{\text {in }}$ (Figure 5a,b) clearly showed a different magnetic mineralogy between shelf and slope sediments, while the distribution of the parameters ARM, SOFT\% and SIRM/ARM (Figure 5d-f) revealed a zone of finer magnetic particles at the western part of the gulf, in accordance to the general sediment transport and settling regime.

Figure 4. The Gulf of Lions (a) and the NW Mediterranean Sea (b). The stations sampled for surface sediments during the EROS-2000 project are shown with white dots. At sites A, B, C, D with depths $>2000 \mathrm{~m}$ short sediment cores were collected. The arrows indicate the positioning of the submarine canyons.

(a)

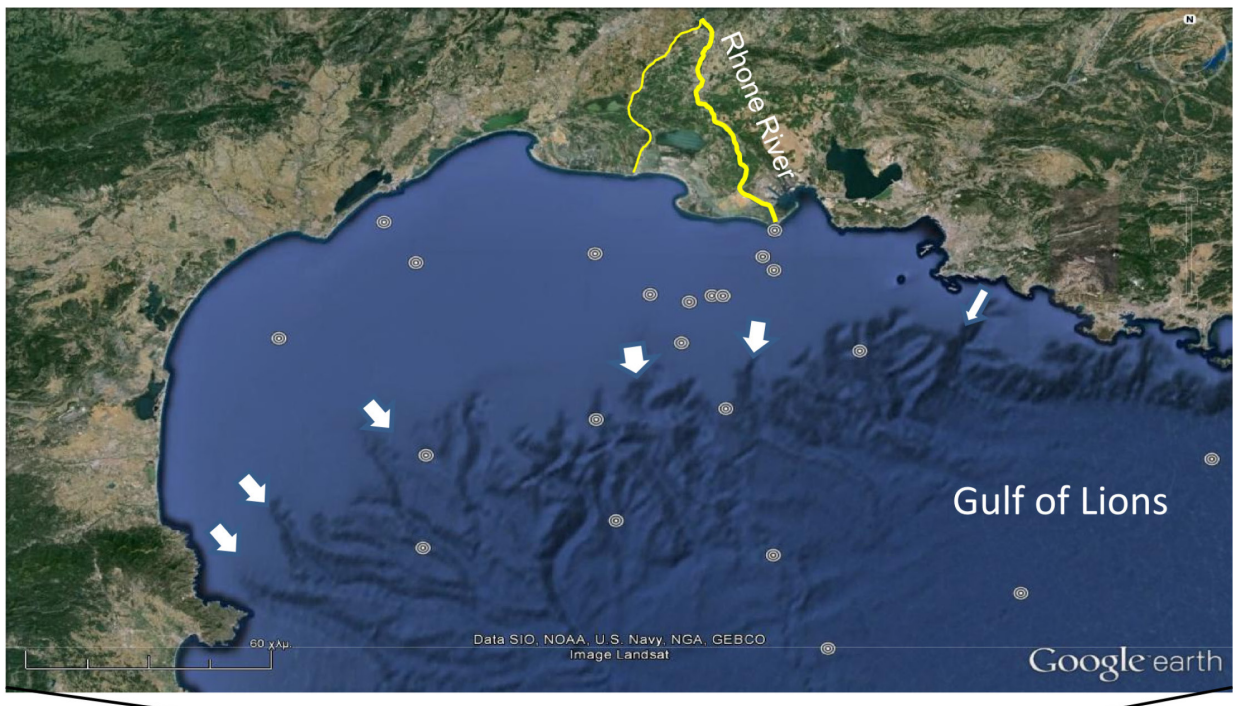

(b)

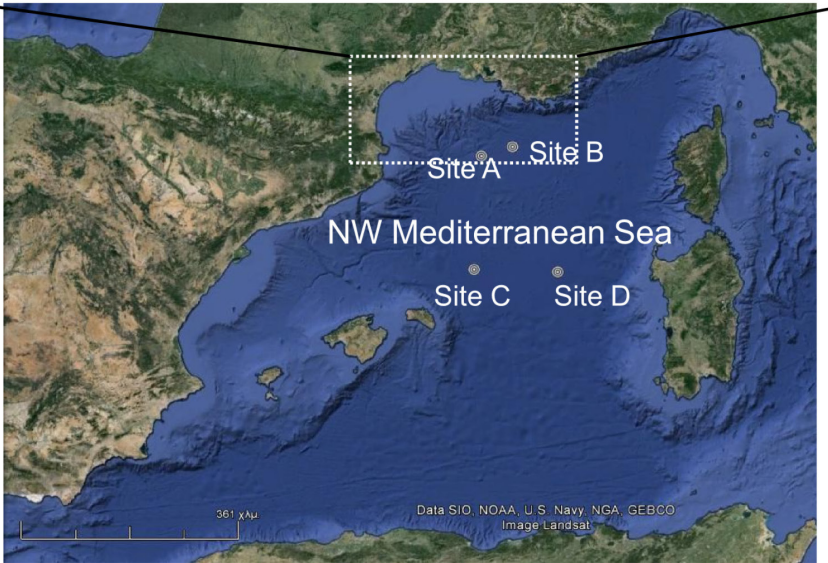


Figure 5. The spatial distribution of the magnetic parameters in the surface sediments of the Gulf of Lions (a) SIRM $\left(\mu \mathrm{A} \cdot \mathrm{m}^{2} \cdot \mathrm{kg}^{-1}\right)$; (b) $\chi_{\text {in }}\left(10^{-8} \mathrm{~m}^{3} \cdot \mathrm{kg}^{-1}\right)$; (c) $\chi_{\mathrm{fd} \%} ;$ (d) ARM $\left(\mu \mathrm{A} \cdot \mathrm{m}^{2} \cdot \mathrm{kg}^{-1}\right)$; (e) SOFT\%; (f) SIRM/ARM.

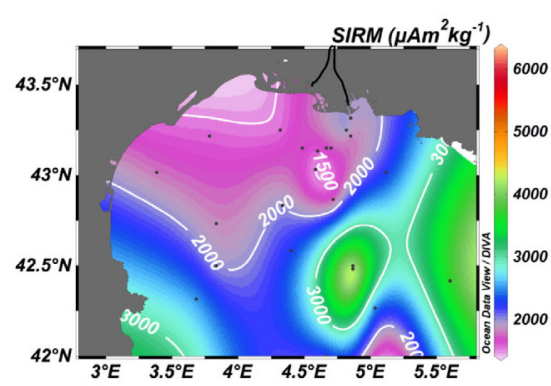

(a)

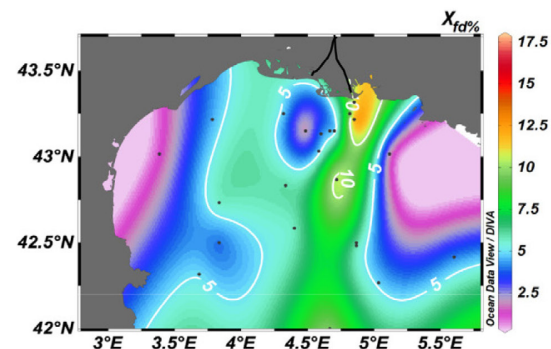

(c)

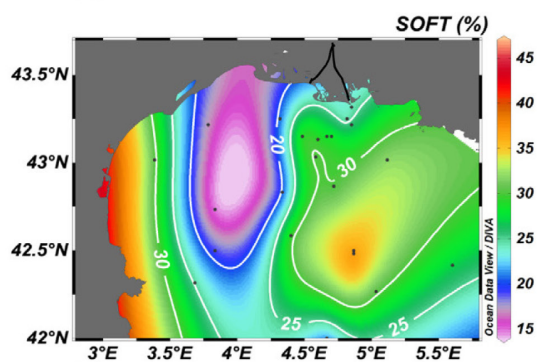

(e)

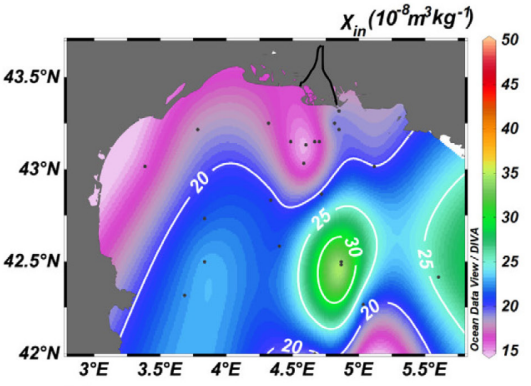

(b)

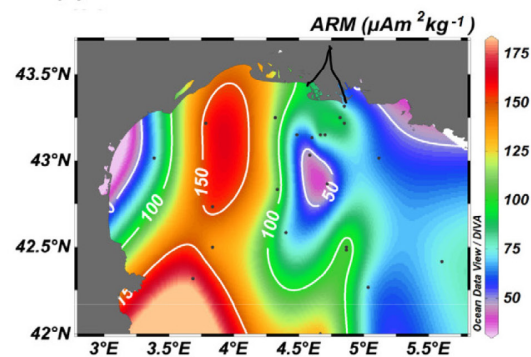

(d)

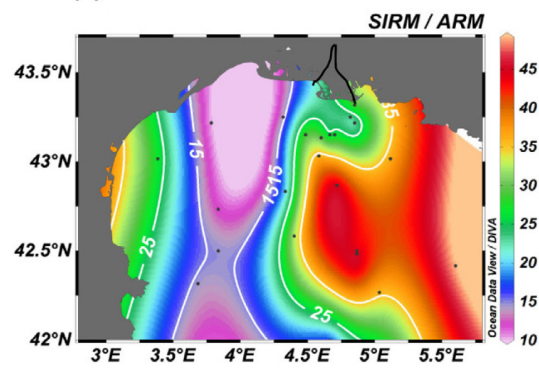

(f)

The vertical distribution of $\chi_{\mathrm{in}}, \mathrm{SIRM}$ and $\chi_{\mathrm{fd} \%}$ of two short sediment cores collected from the deep parts $(>2000 \mathrm{~m}$ ) of NW Mediterranean Sea (sites A and B) is depicted in Figure 6. Based on the sedimentation rates $\left(\sim 0.03 \mathrm{~cm} \mathrm{yr}^{-1}\right)$ reported by Zuo et al. [61], for exactly the same sites, the surface horizon corresponding to about 100 years ago, i.e., at the beginning of the industrial era, is plotted on the profiles.

Maximum values of $\chi_{\text {in }}$ and SIRM at the surface layers indicate a differentiation in nature and texture between surface sediments deposited during the last hundred years and the subsurface ones. This feature was not observed at the profiles of the nearshore stations, where higher sedimentation and mixing rates (from bioturbation and resuspension processes) occurred. It was hypothesized that the surface enhancement of $\chi_{\text {in }}$ and SIRM at the offshore sites was mainly due to atmospherically-transported ferrimagnetic particles discharged at an increasing rate into the atmosphere over the last few decades, as a consequence of rapidly increasing combustion of fossil fuels. In addition, the slightly lower values of the ratio $\mathrm{ARM} / \chi_{\text {in }}$ in the first top $3 \mathrm{~cm}$ provide some evidence of the presence of relatively coarse magnetic grains during the last 100 years. This atmospheric effect became more obvious offshore, due to the lower contribution of magnetically "inert" riverine material there. In fact, atmospheric inputs to the deep-sea sediments appear to prevail $\left(4 \times 10^{6} \cdot \mathrm{t}^{\mathrm{yr}} \mathrm{yr}^{-1}\right)$ over those of terrestrial and riverine origin $\left(1 \times 10^{6} \mathrm{t} \cdot \mathrm{yr}^{-1}\right)[62]$. 
Figure 6. Vertical distribution of $\chi_{\text {in }}\left(10^{-8} \mathrm{~m}^{3} \cdot \mathrm{kg}^{-1}\right)$, SIRM $\left(\mu \mathrm{A} \cdot \mathrm{m}^{2} \cdot \mathrm{kg}^{-1}\right)$ and $\chi_{\mathrm{fd} \%}$ at sites A and $\mathrm{B}$. The profiles of $\mathrm{Pb}$ and $\mathrm{Zn}$ concentration are shown for the same sites (adapted from Nolting and Helder [54]). Horizontal line shows the horizon of surface sediment about 100 years ago.

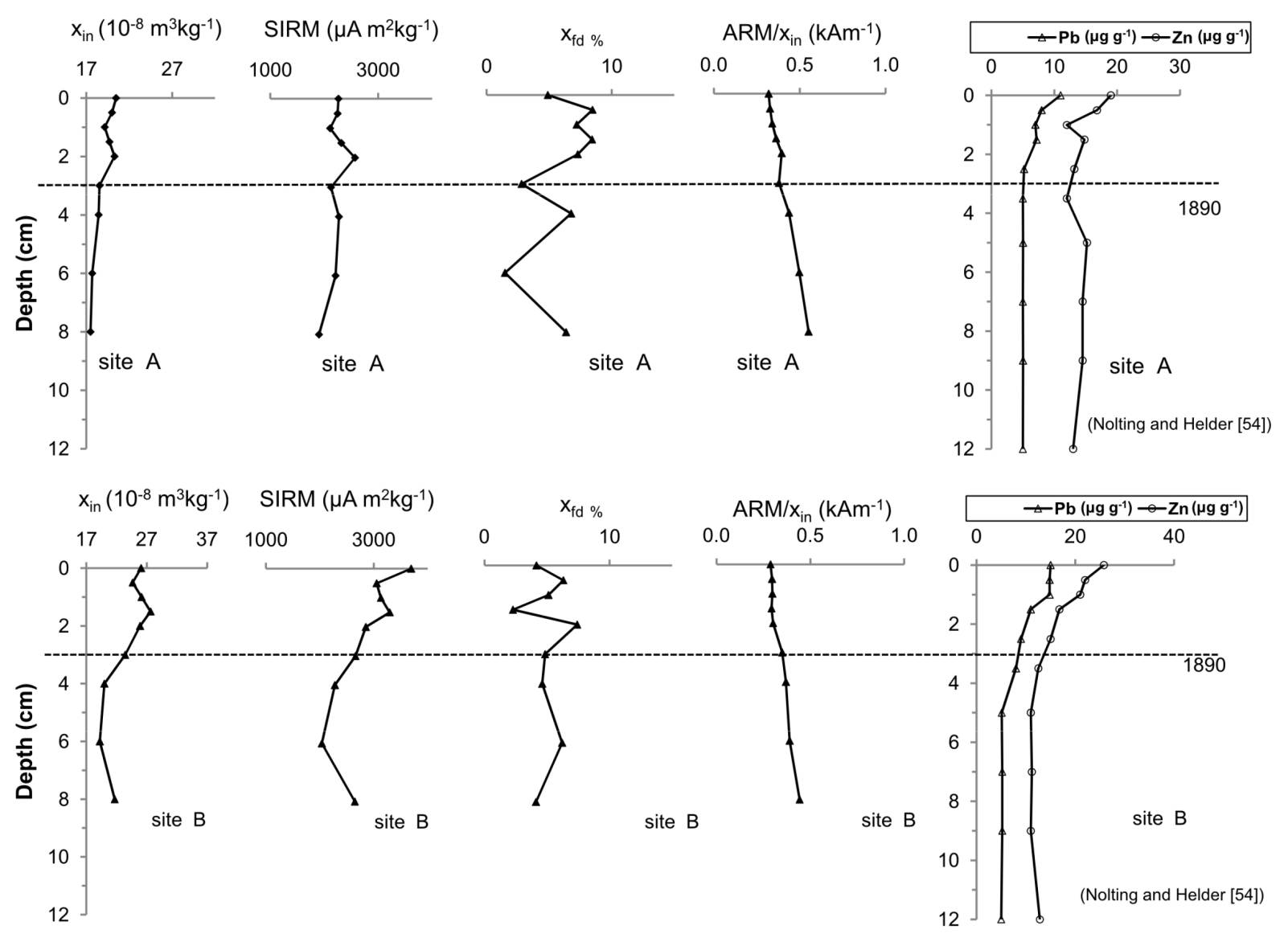

That anthropogenic particles deriving from the European coast find their way by atmospheric long-range transport into the deep-sea sediments of the NW Mediterranean was further supported by the findings of Nolting and Helder [54], Lipiatou and Saliot [63], and Tolosa et al. [64]. These authors, found high concentrations of lead, zinc, and PAHs (Polycyclic Aromatic Hydrocarbons) at the same depth intervals and in the same samples where high $\chi_{\text {in }}$ and SIRM values had been recorded, as shown in Figure 6 for the case of lead and zinc. This was a powerful evidence of the coexistence of contaminants such as PAHs, lead and zinc with ferrimagnetic iron oxides (deriving from a common source, i.e., the combustion of fossil fuels) in atmospheric aerosol particles of $<1 \mu \mathrm{m}$. The preferential association of heavy metals with such aerosol particles in the Mediterranean atmosphere has been demonstrated by Remoundaki et al. [65].

A similar distribution of the magnetic parameters was observed also in the cores of the offshore sites $\mathrm{C}$ and $\mathrm{D}$, farthest from the European continent (Figure 7). At these sites very low sedimentation rates have been found $\sim 0.01 \mathrm{~cm} \mathrm{yr}^{-1}$ [60], so that only the top first $\mathrm{cm}$ of the cores corresponds to the industrial era.

A further question concerned the mechanism whereby such small particles were deposited at great depths. Atmospheric deposition, and particularly the particle fluxes known to occur mainly during the Saharan dust episodes, could play an important role in facilitating the deposition and co-precipitation 
of fine anthropogenic particles (from fossil fuel combustion) from the atmosphere and the water column to the sediments. In order to elaborate our hypothesis we made a magnetic characterization of two aerosol samples collected in Corsica during two different dust episodes in 1986-1987, which were characterized as Saharan derived dust [66]. The magnetic properties of those samples are presented in Table 3.

Figure 7. Vertical distribution of $\chi_{\text {in }}\left(10^{-8} \mathrm{~m}^{3} \cdot \mathrm{kg}^{-1}\right), \operatorname{SIRM}\left(\mu \mathrm{A} \mathrm{m}{ }^{2} \cdot \mathrm{kg}^{-1}\right)$ and $\chi_{\mathrm{fd} \%}$ at sites C and D shown on Figure 4. Horizontal line shows the horizon of surface sediment about 100 years ago.

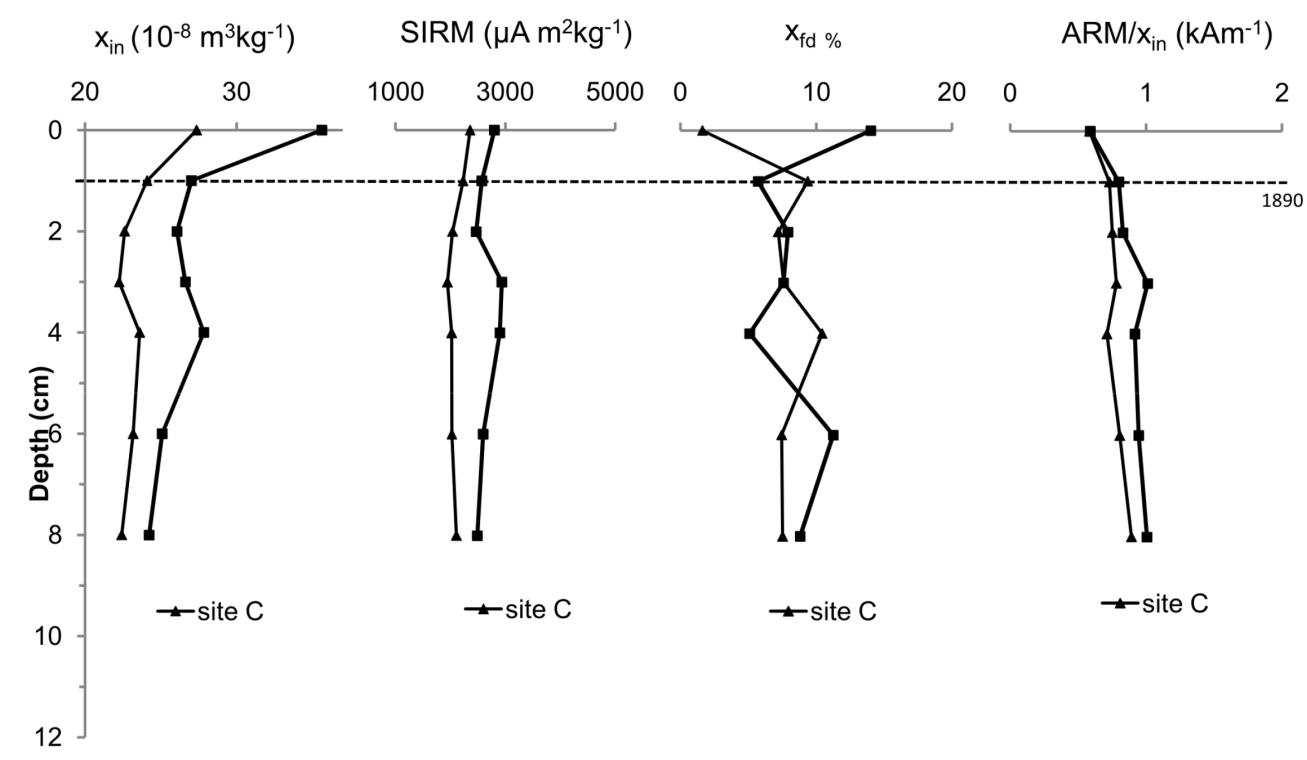

Table 3. Magnetic characterization of aerosol samples collected over the island of Corsica.

\begin{tabular}{|c|c|c|c|c|c|c|c|}
\hline Aerosol sample & $\begin{array}{c}\chi_{\text {in }} \\
\left(10^{-8} \mathbf{m}^{3} \cdot \mathrm{kg}^{-1}\right) \\
\end{array}$ & $\chi_{\mathrm{fd} \%}$ & $\begin{array}{c}\text { ARM } \\
\left(\mu \mathrm{A} \cdot \mathbf{m}^{2} \cdot \mathrm{kg}^{-1}\right)\end{array}$ & $\begin{array}{c}\text { SIRM } \\
\left(\mu \mathrm{A} \cdot \mathrm{m}^{2} \cdot \mathrm{kg}^{-1}\right)\end{array}$ & SIRM/ARM & $\begin{array}{l}\operatorname{SIRM} / \chi_{\text {in }} \\
\left(\mathbf{k A} \cdot \mathbf{m}^{-1}\right) \\
\end{array}$ & IRM $_{-0.3 \mathrm{~T}} / \mathrm{SIRM}$ \\
\hline Dust 1 06/03/86 & 78 & 6 & 119 & 4836 & 41 & 6 & -0.19 \\
\hline Dust 2 06/12/87 & 131 & 12 & 449 & 8706 & 19 & 7 & -0.10 \\
\hline
\end{tabular}

From the values of the IRM $_{-0.3 \mathrm{~T}} / \mathrm{SIRM}$ ratios it becomes clear that in both aerosol samples the antiferromagnetic component (i.e., hematite) was dominant. Nevertheless, the ratios $\chi_{\mathrm{fd}} \%$ and SIRM/ARM, which are more sensitive to magnetic granulometry, indicate that Dust 1 was more affected by coarse magnetic grains. These data imply that the two aerosols collected over Corsica during the dust episodes have probably undergone a different degree of mixing with anthropogenic coarse magnetic particles. In the plot of Figure 8 we compare the magnetic mineralogy of the two dusts with that of the offshore sediments from the NW Mediterranean Sea using the average values of the top centimeters at sites $\mathrm{A}, \mathrm{B}(0-3 \mathrm{~cm} ; n=6)$, and sites $\mathrm{C}$ and $\mathrm{D}(0-1 \mathrm{~cm} ; n=2)$, corresponding to 100 years timespan. At the offshore sites A and B the low $\chi_{\mathrm{fd} \%}(\leq 5 \%)$ and elevated SIRM/ARM ratios (33-40) are recorded, so that these samples are grouped with Dust 1. A second well-defined group is formed by the sediments of sites $\mathrm{C}$ and $\mathrm{D}$ - further offshore - and Dust 2 having elevated $\chi_{\mathrm{fd} \%}(>5 \%)$ and low SIRM/ARM ratios (13-19). These data clearly show that the magnetic signature of the atmospheric particulates is retained in the sediments. Dust 2, characterized as highly antiferromagnetic and therefore with strong 
"Saharan" character, is grouped with the sediments from sites C and D closest to the African coast. Dust 1 which consists of coarser magnetic grains, is grouped with the sediments of sites A and B, closest to the European coast and affected by anthropogenic contaminants as already discussed previously.

The different data obtained for those sites with extremely low sedimentation rates provided strong indications that particles of Saharan origin: (i) can be traced in the deep sediments of the NW Mediterranean Sea by the magnetic methodology (case of sites C and D); (ii) can act as carriers of small quantities of magnetically distinguishable matter of anthropogenic origin existing in the atmosphere, or already deposited in the surface layers of the water column (case of sites A and B). Our data on magnetic parameters provided evidence on the atmospheric versus riverine input of particles and some strong indications about the presence of anthropogenic particles in offshore deep-sea sediments in this region. Moreover, the data indicated that Saharan dust and anthropogenic particles coexisted in the sediments, supporting the hypothesis that Saharan dust episodes could play an important role in facilitating deposition and co-precipitation of anthropogenic particles from the atmosphere and the water column [56,67].

Figure 8. SIRM/ARM versus $\chi_{\mathrm{fd} \%}$ for atmospheric dust samples collected over Corsica and surface sediments from the deep $(>2000 \mathrm{~m})$ NW Mediterranean Sea. Average values for the top centimeters of sediments corresponding to 100 years timespan $(0-3 \mathrm{~cm}$ for sites $\mathrm{A}$ and $\mathrm{B} ; 0-1 \mathrm{~cm}$ for sites $\mathrm{C}$ and $\mathrm{D})$.

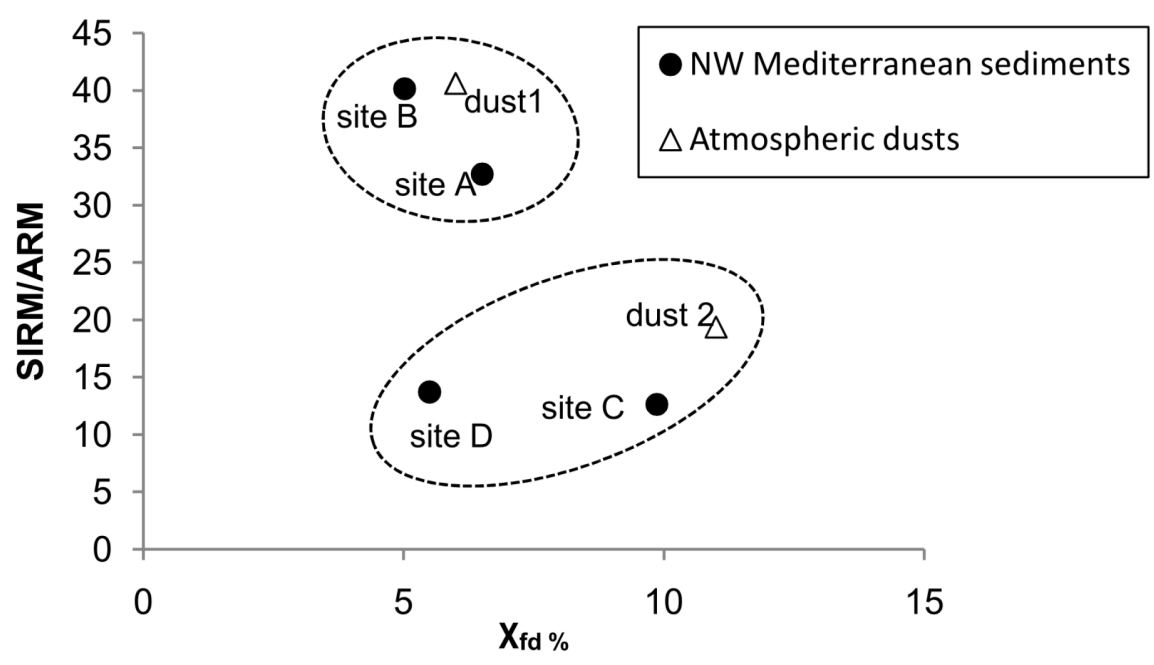

\section{Identification of Geochemical Processes and Transport Pathways from Sources to Sink}

\subsection{The Louros and Acheloos Estuaries}

The Louros and Acheloos rivers are two perennial systems, located in western Greece (Figure 2). The Louros River is $80 \mathrm{~km}$ long and drains an area of approximately $800 \mathrm{~km}^{2}$. Its basin hosts more than 100 large and small agricultural industries [25]. The river discharges at the Amvrakikos Gulf, where its delta together with the Arachthos delta and several lagoons, form a complex, which is designated as a protected wetland under the Ramsar Convention and the EU legislation.

The Acheloos River is the second longest river in Greece $(255 \mathrm{~km})$ and drains an area of $6478 \mathrm{~km}^{2}$. Its basin is not particularly urbanized, nor industrialized, and consists mainly of agricultural land 
$(41 \%$; [68]). The river is heavily fragmented by four large hydroelectric plants. The construction and operation of the dams have significantly altered river's runoff and sediment fluxes at the downstream areas. More than $80 \%$ of the annual sediment flux is retained in the reservoirs, with consequences in the sedimentation processes in the estuary [69].

Geochemical studies at both the Louros and the Acheloos estuaries provide an insight of trace metals behavior in salt-wedge systems. The Louros River mouth is silled by a very shallow bar $(<0.6 \mathrm{~m})$. During low flow $\left(<10 \mathrm{~m}^{3} \cdot \mathrm{s}^{-1}\right)$ periods in summer, saline water penetrates into the estuary along the river bed, and forms a thin (approximately $15 \mathrm{~cm}$ ) salt wedge water mass.

At the Acheloos River mouth, there is a shallow sand bar of 50-80 m width. The water depth at the bar area is less than $1 \mathrm{~m}$ and increases abruptly to more than $40 \mathrm{~m}$ depth in a distance of $3 \mathrm{~km}$ offshore. At periods of limited freshwater supply, the salt-wedge extends to 2-3 km landward from the river mouth. At periods of increased freshwater supply, the fresh-saline water interface obtains a vertical front, which lies close to the river mouth on the marine side of the bar [70].

Early investigations on magnetic properties and trace metals analysis of sediment cores obtained from the estuaries [44] showed that the systems shared a common feature: Trace metal contents followed the distribution of magnetic susceptibility only when sediments were fine-grained. Finer (fine silt and clay) sediments had higher $\chi_{\text {in }}$ values and a soft demagnetization behavior and higher non-lattice trace metals contents. Coarser sediments (sands) had relatively harder demagnetization behavior and most probably a deeper sub-soil or bed origin.

Figure 9 shows characteristic vertical distributions of the magnetic properties of a core obtained from the lower reaches of the Louros estuary. A clear shift from an earlier hematite-like magnetic assemblage to a later soft assemblage is observed. Detailed magnetic properties (ARM, SIRM, IRM ${ }_{-x} / \mathrm{SIRM}_{\text {at }}$ the reverse fields of $-20 \mathrm{mT},-40 \mathrm{mT},-100 \mathrm{mT}$, and $-300 \mathrm{mT}$ ) in the various grain-size fractions [44] confirmed that the sandy particles of the lower sediment layers dominated the hard demagnetization behavior of the bulk sediments. On the contrary, the fine silts and clays of the overlying sediments had high ARM values and low SIRM/ARM ratio values and contributed the most to the respective values of the bulk sediment. Additionally, the uppermost sediments had similar magnetic properties with soil samples taken from the area [44].

It was concluded that the finer particles, rich in soil-derived secondary magnetite, abundant in SD (Single Domain) and SP (Superparamagnetic) grains, were the major carriers of trace metals in both the Louros and Acheloos estuaries. Although the ability of the fines to bind trace metals is well known [21], detailed chemical analysis of water, suspended particles, and sediments conducted later in the Louros [25] and the Acheloos Estuary [24,71] further enlightened the enrichment mechanisms, described in the following paragraphs.

In the Louros estuary, the salt-wedge water mass, sampled by submersible micropumps, had the highest dissolved $\mathrm{Fe}, \mathrm{Mn}, \mathrm{Cu}, \mathrm{Zn}, \mathrm{Ni}$ and $\mathrm{Pb}$ and particulate (in $w / w$ ) $\mathrm{Mn}, \mathrm{Cu}$, and $\mathrm{Zn}$ concentrations compared to the marine and the riverine water masses. A similar enrichment of the loosely held fraction of nearly all metals in the surficial estuarine sediments in relation to the marine ones has also been observed. Figure 10 shows indicative distribution patterns of $\mathrm{Cu}$ in the solution, the suspended particles and the surficial sediments in the Louros system. Moreover, the vertical distribution of trace metals in muddy, cored sediments (that corresponded to the uppermost layers of the soft assemblage of high $\chi_{\text {in }}$ values of our previous research) displayed an upward increasing trend. 
Figure 9. Indicative vertical distributions of $k_{\mathrm{fd} \%}$, and the interparametric ratios IRM $_{-20 \mathrm{mT}} / \mathrm{IRM}_{300 \mathrm{mT}}$ and $\mathrm{IRM}_{-100 \mathrm{mT}} / \mathrm{IRM}_{300 \mathrm{mT}}$ in a core obtained from the lower estuary of Louros River.
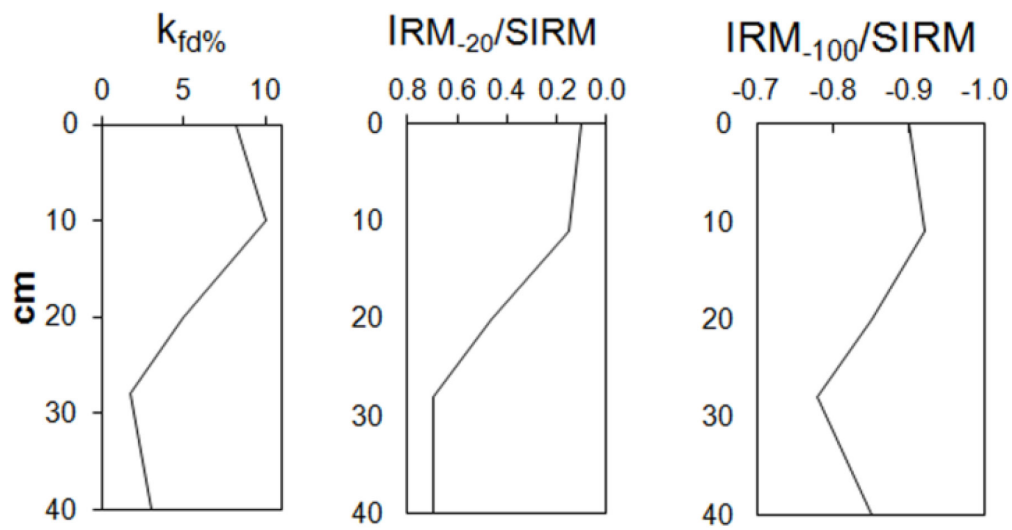

Figure 10. Spatial variation of $\mathrm{Cu}$ in (a) the dissolved phase; (b) the suspended particulates and (c) surface sediments of the riverine (RIV), the salt-wedge (SW) and the marine (MAR) sector of the Louros system; (d) vertical distribution of labile $\mathrm{Cu}$ extracted by $0.5 \mathrm{~N} \mathrm{HCl}$ in a core obtained from the estuary.
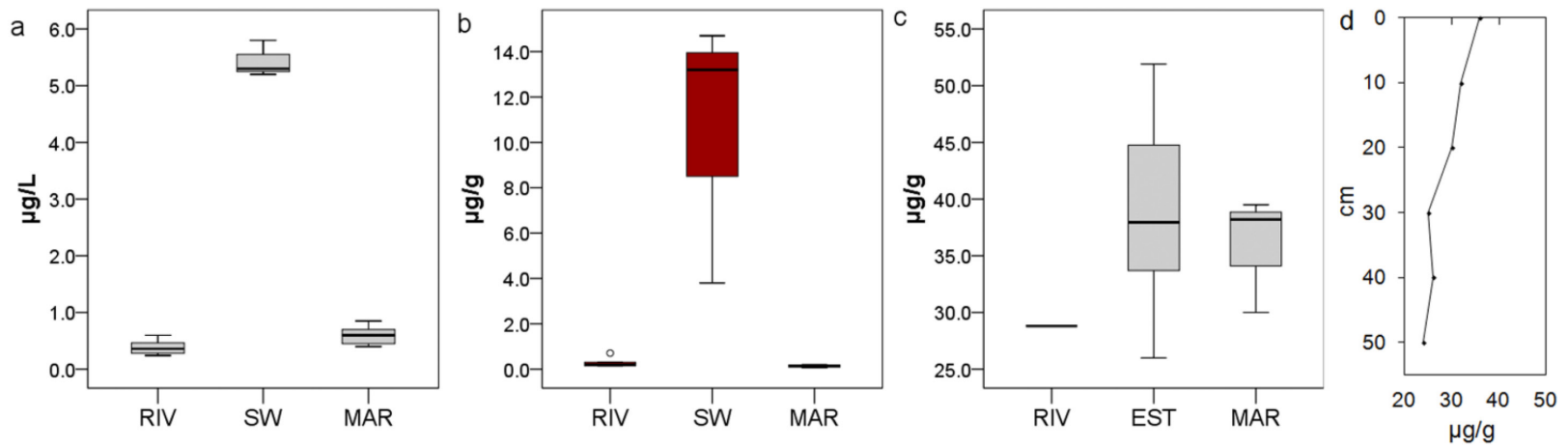

On the basis of these results, it was proposed that the lighter, soil derived particles of higher $\chi_{\text {in }}$ values and the highest potential to remain in suspension, once they reached the lower estuary became entrapped and recycled within the landward moving saline layer, the salt-wedge. These particles were enriched in trace metals by anthropogenic sources, as well as by in situ processes. The latter were postulated by the increase of particulate $\mathrm{Al}, \mathrm{Fe}$, and $\mathrm{Mn}$ extracted by dilute $\mathrm{HCl}$ [25]. Formation of authigenic $\mathrm{Al}-\mathrm{Fe}$ (and $\mathrm{Mn}$ ) oxyhydroxides occurs in the salt-stress interface, where the low $\mathrm{pH}$ riverine water (in this study $\mathrm{pH}$ : 7.1-7.3) meets the saline water of higher $\mathrm{pH}$ (in this study $\mathrm{pH}>7.8$ ) [72,73]. Co-precipitation processes of trace metals with the authigenic oxyhydroxides gave rise to particulate trace metal concentrations. At the same time, trace metals were released to solution through desorption processes, favored by the long residence time of the salt-wedge water mass $[74,75]$. The relative enrichment of trace metals in the surface layers of the cores was due to the washing of fine, soil-derived particles contaminated by recent anthropogenic activities with some contribution of re-precipitation processes occurring in the estuarine zone.

In the Acheloos estuary, trace metals accumulated in the sediments of three distinct zones: (a) the upper estuary, where the upper boundary of the salt-wedge was observed during periods of low flow, 
(b) the sill bar located at the river mouth; and (c) the offshore station of the lower estuary at the boundaries with the marine sector. Figure 11 presents the distributions of $\mathrm{Al}, \mathrm{Fe}$, and $\mathrm{Zn}$ extracted by $0.5 \mathrm{~N} \mathrm{HCl}$ in the surface sediments of the system. Similar distribution patterns were also observed for other trace metals [71].

Figure 11. Upper panel: the distribution of metals extracted by $0.5 \mathrm{~N} \mathrm{HCl}$ of the surface sediments of the Acheloos estuary and their relative enrichment in the upper boundary of SW (a), the sill bar (b) and the offshore station (c); Lower panel: vertical distributions of f1 (easily exchangeable), f2 (inorganic), f3 (organic), and f4 (residual) fractions of Zn extracted by SES (1) of Table 1 in sediments of short cores obtained from zones (a), (b), and (c).
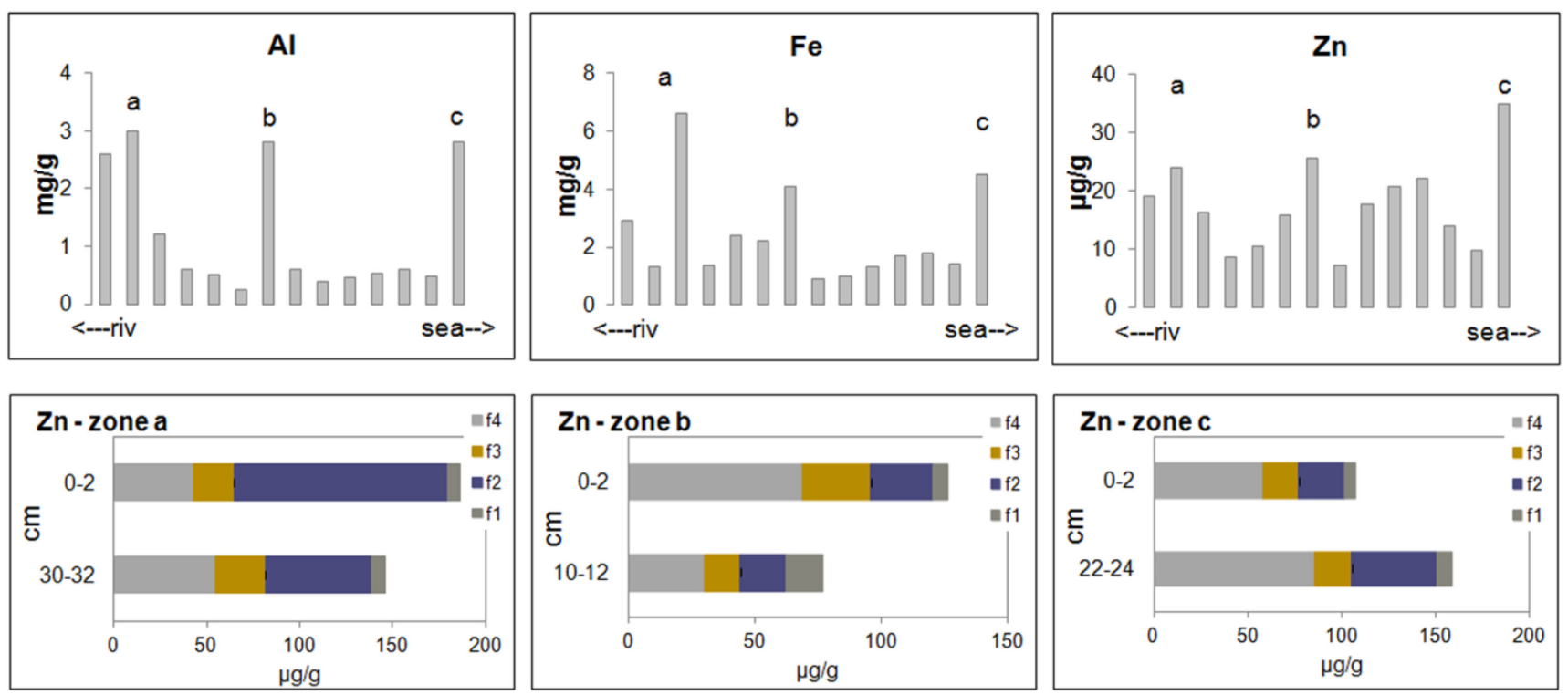

The accumulation of $\mathrm{Al}, \mathrm{Fe}$, and trace metals at the offshore station was attributed to the flushing of fine particles out of the estuarine zone and deposition at great distances. The mud (silt and clay) fraction of the offshore sediment samples accounted for $99 \%$ of the bulk sediment. The transport and deposition of fines at great distances was also evidenced by the increase of the small suspended particles (with diameter $<8 \mu \mathrm{m}$ ) from $4.6 \%$ of the total SPM in the riverine sector to $8 \%$ in the estuarine sector and to $20 \%$ in the marine sector [24].

The increase of labile $\mathrm{Al}$ and $\mathrm{Fe}$ (and Mn, not shown) in the sediments of the upper boundary of the salt wedge indicated, as in the case of the Louros Estuary, the coagulation of Al-Fe-Mn oxyhydroxides at the "salt-stress" interface and subsequent sedimentation. On the other hand, accumulation of metals at the sill bar demonstrated the importance of the geomorphology and the hydrodynamics of the system: the sill bar acts as a natural barrier for particulates under regular flow conditions; under low flow conditions, when seawater intrudes the estuary, particles could be recycled back in the landward direction, along with the salt wedge water mass, or flushed away under high flow conditions. The employment of magnetic measurements in SPM collected seasonally and especially during flooding events or evident seawater intrusion in the estuary, may confirm the described transport of particulate matter.

In the sediments of the estuarine station (Figure 11) the most abundant fraction of $\mathrm{Zn}$ was the inorganic fraction, consisting $80 \%$ of labile $\mathrm{Zn}(62 \%$ of total $\mathrm{Zn})$ in the surface layer, and $63 \%$ of labile $\mathrm{Zn}(39 \%$ of total $\mathrm{Zn})$ in the subsurface layer, indicating that $\mathrm{Zn}$ was predominantly bound to 
Fe/Mn oxyhydroxides and carbonates. This finding is supportive of and supported by the in situ coagulation and co-precipitation processes of Al-Fe-Mn oxyhydroxides that occur in the estuarine zone. The contribution of the inorganic fraction to labile $\mathrm{Zn}$ content slightly reduced in the sediments of the sill bar (43\% of labile $\mathrm{Zn}$ in the surface layer and $39 \%$ in the subsurface one), and increased again (to $62 \%$ of labile $\mathrm{Zn}$ ) in the subsurface sediments of the offshore station.

Considering the temporal variations, Figure 11 depicts that the surface sediments of the estuarine zone were relatively enriched in the estuarine zone compared to the subsurface ones and relatively depleted in the offshore station. Combining temporal and spatial trends, two critical conclusions could be drawn: Firstly, the observed increase in the surface sediments reflects the recent contamination from anthropogenic activities in the entire Acheloos basin, combined with a reduction of fluxes of inert detrital particles (suggested by magnetic measurements), that dilutes the anthropogenic and the authigenic component of trace metals. Secondly, the decrease of labile of $\mathrm{Zn}$ (and also other metals) in the surface sediment layer of the offshore station in relation to the subsurface one, suggests that in the past, under a different hydrological regime of higher river discharge, transport and deposition at the offshore stations was more pronounced than is today.

The combination of trace metal and magnetic studies of the Louros and Acheloos estuaries shows the vulnerability of these systems with respect to trace metal transport and processes under unstable hydrological regimes. A decrease of the river flows and sediment fluxes, through dam construction, water abstraction for irrigation purposes, or even climate changes, will favor the development and stability of the salt wedge, thus, will intensify the processes that are responsible for the relative enrichment of trace metals in the estuarine zone. Episodic flooding of the estuary could release the finest, unconsolidated particles, enriched in trace metals into the adjacent sea.

All the above point to the need for an integrated management of water resources and the coastal zone informed by the above findings.

\subsection{The Asopos Estuary}

The Asopos River (Figure 1) is an intermittent river, of very wide flow variations depending mainly on rainfall volumes, is $63 \mathrm{~km}$ long and has a drainage basin of $790 \mathrm{~km}^{2}$. The extreme variation of its hydrological regime results in a narrow and highly unstable fresh-saline water interface, and consequently in complex traces metal geochemical transformations in the estuarine zone. The Asopos River is characterized by the degradation of the environmental status, due to effluent discharges from numerous industrial plants, including metallurgies and metal furnishing industries, factories related to textile and dyes production, as well as various food and chemical industries [32]. Trace metal contents of sediment samples obtained from the riverine, estuarine and coastal marine sectors of the system did not follow a common distribution pattern: Iron, $\mathrm{Cr}$, and $\mathrm{Ni}$ gradually decreased towards the sea; $\mathrm{Cadmium}, \mathrm{Cu}$, and $\mathrm{Zn}$ became enriched in the estuarine sector, whereas $\mathrm{Mn}$ and $\mathrm{Pb}$ levels were lower in the estuarine sector in relation to riverine and the marine ones (Figure 12). The employment of single and sequential extractions showed that the major fraction $(>80 \%)$ of the first group of metals (Fe, $\mathrm{Cr}$ and $\mathrm{Ni}$ ) was lattice-held, implying a lithogenic origin. The lattice-held fraction of these metals followed a seaward decreasing trend. On the other hand, the labile fractions of $\mathrm{Fe}, \mathrm{Cr}$, together with the labile fractions of $\mathrm{Cu}, \mathrm{Cd}$, and $\mathrm{Zn}$ increased in the sediments of the estuarine sector (Figure 12). 
The processes responsible for the accumulation of metal labile species in the estuarine sediments could be inferred by the results of sequential extractions: For almost all the metals studied, an increase of the acid-soluble fraction was observed, implying that adsorption processes of the dissolved and colloidal forms onto suspended sediments are favorable in this sector. Furthermore, there was an increase of Fe, $\mathrm{Cu}, \mathrm{Cd}, \mathrm{Zn}$, and $\mathrm{Cr}$ reducible fractions, inferring precipitation of oxyhydyroxides and co-precipitation of trace metals with Fe-oxides. Finally, $\mathrm{Cr}$ exhibited an increase in the oxidizable fraction in the estuarine sector, implying that coagulation and precipitation of dissolved and colloidal complexes of $\mathrm{Cr}$ with organic matter is taking place in the intermixing zone.

Figure 12. Distributions of $\mathrm{Me}$ to $\mathrm{Al}$ ratios (except for $\mathrm{Cr}$ ) in the upper panel, of the concentrations of labile metal fractions (in $\mathrm{mg} / \mathrm{kg}$ ) extracted by $0.5 \mathrm{~N} \mathrm{HCl}$ (dilute $\mathrm{HCl}$ ) in the middle panel and by SES (2) (in $\mathrm{mg} / \mathrm{kg}$ ) in the lower panel in the riverine (RIV), estuarine (EST) and marine (MAR) sector of the Asopos system. In the box plots, the boxes contain the middle $50 \%$ of the data; the lower hinge (edge of the box) represents the 25 th percentile and the upper hinge the 75 th percentile; the horizontal line within the box is the median value; whiskers show the range of values falling within 1.5 times the H-spread, which is defined as the difference between the hinges; in the absence of outliers, whiskers represent the minimum and maximum data values; outliers are denoted with circles and are defined as the values between 1.5 and 3 times the $\mathrm{H}$-spread; extreme values are denoted with asterisks and are defined as the values $>3$ times the $\mathrm{H}$-spread. In the lower panel, $\mathrm{fl}$, $\mathrm{f} 2$ and $\mathrm{f} 3$ are the acid soluble, the reducible and the oxidizable fractions, respectively.
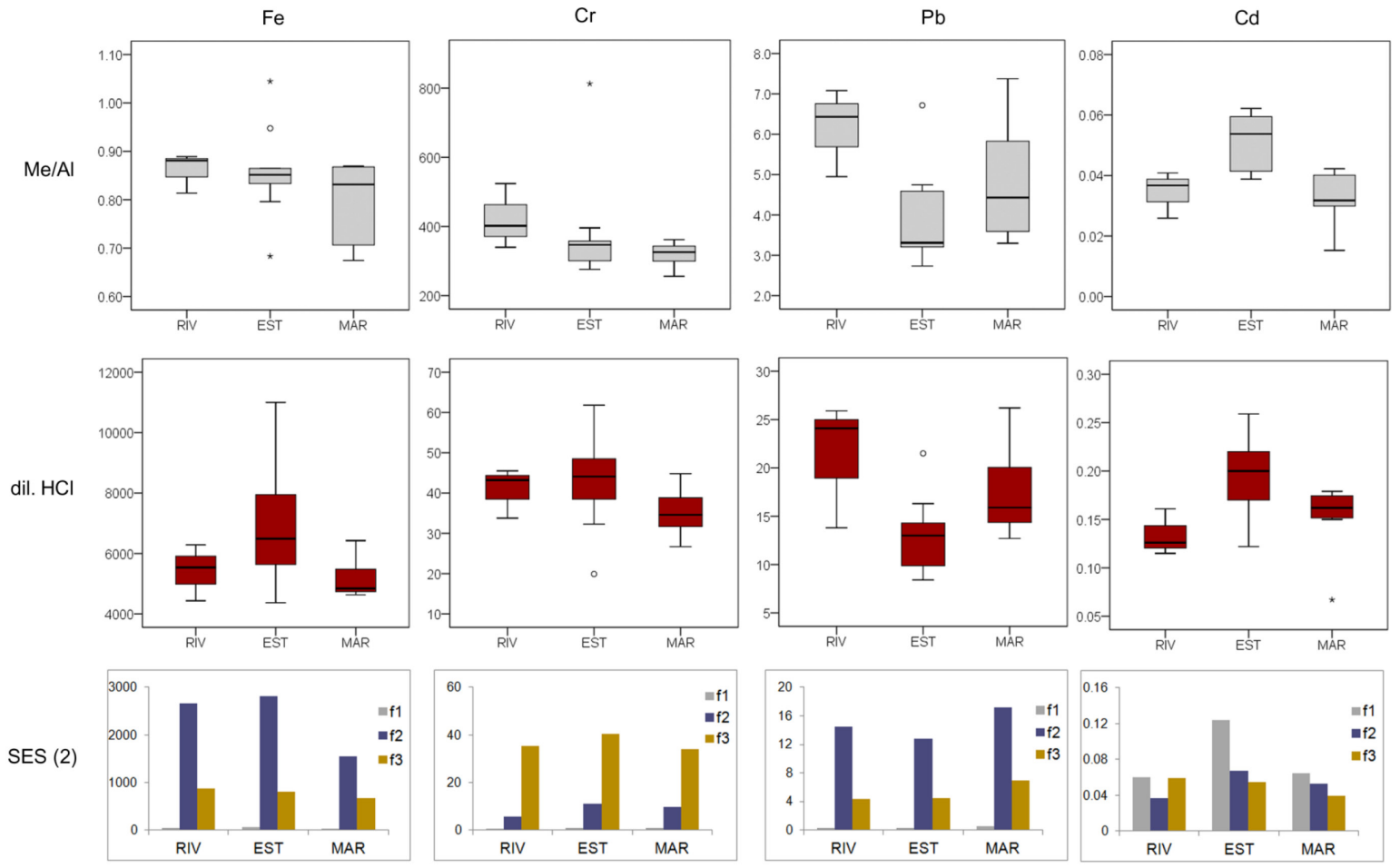

By the above results it is suggested that the distribution patterns of the trace metals studied are defined by a combination of several complex processes that are related to the origin of trace metals, their interchangeable speciation, as well as physical factors that control their transport pathway from the sources to the depositional environment. 
Magnetic characterization of surface sediments shed light on the relevant processes and the transport mechanisms to the adjacent sea, leading to a better understanding of the functioning of Asopos River, but also of intermittent rivers in general.

Table 4 summarizes the results of measurements of the selected magnetic parameters defined in Table 2 . The relatively high values of $\chi_{\text {in }}$, combined with the low values HARD (\%), and the values of $\mathrm{S}_{-100}$ ratio indicate the predominant contribution of the ferrimagnetic minerals over the antiferromagnetics. Magnetic susceptibility is reversibly correlated with the clay fraction $(r=-0.669 ; p<0.01)$ suggesting that the magnetic minerals are concentrated in the coarser grains. These findings, together with the values of $\chi_{\mathrm{fd}} \%$ that do not exceed 5.5\%, point to the lithogenic origin of the magnetic particles, deriving from parent minerals $[17,76]$. Interestingly, $\chi_{\text {in }}$ is positively correlated to the lattice-held $\mathrm{Cr}$ and $\mathrm{Ni}$ determined by sequential extractions $(r=0.647$ and 0.726 , respectively; $p<0.05)$. Both metals are structural components of chromites that derive from the weathering of ultramafic rocks, outcropping in the Asopos drainage basin. Although chromite is among the "less common" magnetic minerals, is one of the more resistant minerals in nature and together with other $\mathrm{Fe}-\mathrm{Cr}$ spinels could represent a significant proportion of relict magnetic assemblage [77].

Looking in detail the magnetic properties of estuarine sediments, data of Table 3 show that all magnetic parameters vary widely within this sector, suggesting variations in the concentration, granulometry and mineralogy of magnetic minerals. In turn, these reflect changes in allochthonous inputs, authigenic inputs, and/or post depositional diagenesis [76]. In the following paragraphs an attempt is made to consider the contribution of each of the aforementioned factors in the variation of magnetic signal:

In the estuary, $\chi$ and SIRM displayed a linear relationship $(r=0.973 ; p<0.01)$, which is indicative of a predominantly monomineralic control of the magnetic signal [78]. Taking into account the low contents of antiferromagnetic minerals, as implied by the parameter HIRM, it can be deduced that ferrimagnetics dominate the magnetic mineralogy. The interparametric ratio SIRM/ $\chi_{\text {in }}$ increased in this sector, and attained values ranging from 16.4 to $27.4 \mathrm{kA} \cdot \mathrm{m}^{-1}$ (Table 3). Given the linear relationship of SIRM and $\chi_{\text {in }}$, these relatively high values imply the decrease of magnetic grain-sizes [78]. The increased contribution of SD grains could be attributed to authigenesis of biogenic magnetite in the form of bacterial magnetosomes [35,79]. The latter process is apparently favoured in the Asopos system stimulated by the stagnation of water in the outlet during low, or no flow conditions paralleled by the high inputs of nutrients and organic matter. It is worth-mentioning that TOC (Total Organic Carbon) concentrations in the waters of the Asopos River reaches $30 \mathrm{mg} / \mathrm{L}$, particularly during periods of low flow at the stagnant estuarine waters [80].

In the estuarine sector, the $\mathrm{SIRM} / \chi_{\text {in }}$ ratio attains the highest value $\left(27 \mathrm{kA} \cdot \mathrm{m}^{-1}\right)$ within the Asopos system. $\mathrm{SIRM} / \chi_{\text {in }}$ values $>30 \mathrm{kA} \cdot \mathrm{m}^{-1}$ indicate the presence of greigite [7,77]. Because greigite is unstable during weathering and transport, when present in depository environments, an authigenic origin is strongly indicated [77]. Due to the high supply of readily oxidizable organic matter and subsequent degradation, formation of anoxic micro-environments in near surface sediments, at least temporarily, is expected to take place in near surface sediments.

Although the content of high coercivity minerals (e.g., hematite) is relatively low throughout the system, the hard component (\% HARD; Table 4) increased towards the estuarine and the marine sector. This increase suggests the addition of small amounts of antiferromagnetic minerals. 
Table 4. Summary statistics data of magnetic parameters in sediments of the riverine (RIV), the estuarine (EST) and the marine (MAR) sectors of the Asopos River system.

\begin{tabular}{|c|c|c|c|c|c|c|c|c|c|c|}
\hline Sector & $\begin{array}{c}\text { Statistics } \\
\text { data } \\
\end{array}$ & $\begin{array}{c}\chi_{\text {in }} \\
\left(10^{-8} \mathrm{~m}^{3} \mathrm{~kg}^{-1}\right) \\
\end{array}$ & $\chi_{\mathrm{fd} \%}$ & $\begin{array}{c}\text { SIRM } \\
\left(\mathrm{mA} \mathrm{m}^{2} \mathrm{~kg}^{-1}\right)\end{array}$ & 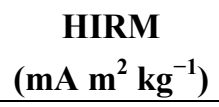 & $\mathbf{S}_{-100}$ & 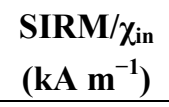 & HARD (\%) & SOFT (\%) & $\begin{array}{c}\text { Modified } \\
\text { L-ratio } \\
\end{array}$ \\
\hline \multirow{3}{*}{ All data } & mean $\pm \mathrm{sd}$ & $66.4 \pm 18.2$ & $3.54 \pm 1.42$ & $12.0 \pm 4.5$ & $0.21 \pm 0.11$ & $-0.749 \pm 0.042$ & $17.8 \pm 3.7$ & $1.77 \pm 0.59$ & $31.2 \pm 6.9$ & $0.14 \pm 0.05$ \\
\hline & median & 71.2 & 3.56 & 11.2 & 0.19 & -0.750 & 16.7 & 1.81 & 28.1 & 0.16 \\
\hline & $\min -\max$ & $32.1-89.4$ & $0.82-5.49$ & $5.7-24.3$ & $0.09-0.44$ & $-0.810-(-0.680)$ & $13.1-27.4$ & $0.86-2.77$ & $24.8-48.0$ & $0.07-0.25$ \\
\hline \multirow{3}{*}{ RIV } & mean $\pm \mathrm{sd}$ & $79.2 \pm 7.6$ & $3.03 \pm 1.15$ & $12.8 \pm 2.3$ & $0.12 \pm 0.02$ & $-0.777 \pm 0.035$ & $16.1 \pm 2.2$ & $0.90 \pm 0.04$ & $30.9 \pm 2.8$ & $0.08 \pm 0.01$ \\
\hline & median & 79.7 & 3.53 & 12.1 & 0.11 & -0.780 & 17.0 & 0.92 & 30.7 & 0.08 \\
\hline & $\min -\max$ & $71.3-86.5$ & $1.71-3.84$ & $10.9-15.4$ & $0.09-0.14$ & $-0.810-(-0.740)$ & $13.7-17.8$ & $0.86-0.93$ & $28.1-33.8$ & $0.07-0.09$ \\
\hline \multirow{3}{*}{ EST } & mean $\pm \mathrm{sd}$ & $59.3 \pm 24.3$ & $2.97 \pm 1.43$ & $12.8 \pm 7.1$ & $0.26 \pm 0.15$ & $-0.735 \pm 0.053$ & $20.7 \pm 4.1$ & $2.02 \pm 0.6$ & $33.5 \pm 10.7$ & $0.16 \pm 0.06$ \\
\hline & median & 52.3 & 2.93 & 11.0 & 0.21 & -0.720 & 20.6 & 2.1 & 27.4 & 0.16 \\
\hline & $\min -\max$ & $32.1-89.4$ & $0.82-5.45$ & $5.73-24.3$ & $0.12-0.44$ & $-0.800-(-0.680)$ & $16.4-27.4$ & $1.11-2.77$ & $24.8-48.0$ & $0.07-0.25$ \\
\hline \multirow{3}{*}{ MAR } & mean \pm sd & $69.4 \pm 5.0$ & $4.58 \pm 1.02$ & $10.9 \pm 1.1$ & $0.21 \pm 0.02$ & $-0.750 \pm 0.026$ & $15.7 \pm 1.4$ & $1.9 \pm 0.2$ & $29.0 \pm 1.8$ & $0.16 \pm 0.03$ \\
\hline & median & 68.6 & 5.06 & 10.8 & 0.22 & -0.760 & 16.1 & 1.9 & 28.4 & 0.16 \\
\hline & $\min -\max$ & $64.6-76.3$ & $2.78-5.49$ & $9.7-12.5$ & $0.18-0.23$ & $-0.780-(-0.710)$ & $13.1-17.1$ & $1.6-2.3$ & $27.5-32.0$ & $0.11-0.19$ \\
\hline
\end{tabular}


In the estuary, $\mathrm{S}_{-100}$ varies widely and in detail does not correlate very well with HIRM (data not shown). This divergence between $\mathrm{S}_{-100}$ and HIRM may be indicative of coercivity changes of the canted antiferromagnetic assemblage. Liu et al., [39] proposed the use of the $L$-ratio to establish the extent to which the antiferromagnetic component is uniform in a given suite of samples, even in the presence of a strong ferrimagnetic signal. In this study, the modified $L$-ratio was employed (the HARD IRMs obtained by DC demagnetization), which is comparable to the original $L$-ratio [40,41].

In the riverine and marine sector the modified $L$-ratio remains relatively constant $(\approx 0.1$ and 0.2 respectively) and in each subset of data HIRM and the modified $L$-ratio are not correlated. These stable $L$-ratios indicate that the variations of HIRM are dominantly caused by changes in the concentration of the canted antiferromangetics. In contrast, in the estuarine sector, the modified $L$-ratio and HIRM have a positive correlation $(r=0.771, p=0.001)$, which indicates that the observed HIRM changes are controlled by changes in the coercivity, rather than by the concentration of the antiferromagnetic minerals. Coercivity variations are associated, among other factors (e.g., changes in the relative proportion of goethite and hematite or in the degree of aluminium substitution), with hematite grain size [39-41], which in turn, could imply diagenetic dissolution of hematite [39].

The next question to consider is the transport pathway of the particles to the marine sector. The decrease of SOFT\% and the increase of $\chi_{\mathrm{fd} \%}$ (Table 4) suggest the sorting of magnetic grains and the increasing contribution of superparamagnetic (SP) grains derived from the top soil material. This is in accordance with the increase of the finest fractions (silt and clay) of the bulk sediments, which constitute more than $90 \%$ in the offshore, marine sediment samples [32]. Considering the magnetic mineralogy of the marine sediments, demagnetization parameters $\left(\mathrm{S}_{-100}, \mathrm{~B}_{\mathrm{cr}}, \mathrm{HARD} \%\right.$, HIRM) show again the predominance of ferrimagnetic minerals. However, the contribution of the canted antiferromagnetics remains rather stable compared to the estuarine sector, suggesting that Fe oxyhydroxides are eventually transported and deposited in the offshore, marine stations of the systems. X-ray Diffraction analysis showed the presence of kaolinite, illite, smectite and chlorite in the offshore, marine sediments [32]. Because both phases (Fe oxyhydroxides and clays) effectively scavenge trace metals through adsorption and co-precipitation processes $[1,21,22]$, their presence in the marine sediments, provide clear evidence of the transport pathway of trace metals from the fluvial to the coastal marine environment.

By combining chemical analysis and magnetic measurements, the following conclusions could be drawn:

The ferrimagnetic component, which originates mainly from the parent materials of the river basin, is concentrated in the coarser fraction of sediments and exhibits a downstream decreasing trend in its concentration and grain size (sorting). Trace metals of lithogenic origin follow the same trend. In the estuary, under the prevailing conditions of long residence time of water rich in easily degradable organic matter, a series of redox reactions, sorption and flocculation/precipitation processes occur, resulting in the relative enrichment of the authigenic component of magnetic particles and the accumulation of labile species of metals in the unconsolidated sediments of the narrow, fresh-saline water intermixing zone. Some coarser particles (mainly of lithogenic origin) are transported to the sea during the high flow periods of the river and the sporadic flood events. What are easily transported, even under regular flow conditions, are the very fine, metal-rich particles of fluvial, anthropogenic, and authigenic origin. 


\section{Some Management Aspects and Conclusions}

In the previous parts of this article we demonstrated through a series of case studies, the valuable information resulted from the full integration of mineral magnetic measurements in the geochemical research of the Laboratory of Environmental Chemistry of the University of Athens dealing with a variety of fluvial, estuarine, coastal and offshore marine systems.

The studies of the Gulf of Elefsis allowed for the identification of the major industrial trace metal pollution source in the area, allowed for the assessment of the area impacted from the pollution originating from a major point source. Through this study we were able also to demonstrate and monitor the results of remediation of the systems through the installation of technologies, reducing both the atmospheric emissions and the effluent discharges to the gulf.

The latter improvements were the consequence of introduction of regulations on emissions and BATs by enforcing the relevant legislative provisions implementing the EU Directives, particularly those related to the pollution of aquatic environment (EC 76/464/EEC) and those on industrial pollution (EC 96/61/EC and the modified IPPC 2008/1/EC). In the Elefsis case, we examined three major aspects: First, the geochemical aspect including trace metal and magnetic minerals concentrations and distribution, as well as sediment chronology data. Second, the technological aspect including the chronological evolution of the production and pollution prevention technologies. Third, the operational-economic aspect, including the raw material and energy input, the specific and overall volumes and types of products of the specific installation. By combining the three aspects, we are in the position to quantify the evolution of pollution load and assess the direct impacts of the management strategies followed and the investments made. Further on the impact the pollution prevention, legislation, policies, strategies and action plans could be assessed.

The above investigation is extremely important and feasible and it is the scope of an ongoing research in the framework of the "Horizon 2020 to depollute the Mediterranean" with prospects of assessing the iron and steel mills sector contribution to the pollution of the entire Mediterranean, in order to provide remediation measures in cooperation with all relevant stakeholders.

The particular example for the Gulf of Elefsis indicates the great potential and valuable contribution of targeted multidisciplinary research to integrated management, in this case in ICZM (Integrated Coastal Zone Management).

The other example of the Gulf of Elefsis indicates that combined magnetic and trace metal studies in sediments could contribute in addressing another fundamental question raised in management and regulatory approaches, such as IWRM/WFD, MSFD and MSP (Maritime Spatial Planning) and ECAP, namely the establishment of background trace metal levels.

The examples of all fluvial and estuarine systems allow for the identification of the major carrier phases and transport pathways of trace metals from point or diffused sources of the corresponding river basin to the adjacent estuaries and marine systems. They also allow for the understanding of major diagenetic processes occurring in the system as a result of particular changes in the continuity, seasonality, volume and pattern of the river flow and a variety of emerging pressures. Most of them could be directly attributed to specific anthropogenic interventions (such as construction of dams, identifiable changes in land uses, etc.) and/or particular industrial or urban discharges, changes in the agricultural practices, etc. 
The example of the Gulf of Lions and the fact that airborne metal pollution from combustion are rapidly accumulated to the deep sea sediments through specific mechanisms may also be useful, not only to MSP but also to reconsidering the relevant significance of measures addressing different pollution sources or pathways (e.g., atmospheric vs. wastewater/fluvial ones).

The above are critically connected to past, present, and future priorities, policies, impacts and eventual management measures of the so-called DPSIR policy cycle (Driving forces, Pressures, State, Impact, Responses), which is in the root of all integrated management approaches. DPSIR is a causal framework for describing on the one hand the interactions between society and the environment, and one the other hand, key phases in policy development and intervention adopted by the European Environment Agency [23]. This approach has been applied recently in various ways by scientists and managers, in an attempt to close the gaps between scientific evidence, management, and decision making $[4,69]$.

Based on the techniques involved in the case studies presented we may suggest a broad methodological strategy to facilitate trace metal management in rivers, estuaries, coastal areas and the marine environment in general, with emphasis to geochemical and mineral magnetic measurements and related techniques. The scheme presented in Figure 13 indicates briefly the links between scientific research and the policy cycle. The scheme may be considered in conjunction and as an evolution of that proposed by Oldfield et al. [55], in the early 1980s, involving the entire watershed and based on the ecosystem concept.

Figure 13. The concept of a methodological strategy integrating trace metal (TM) management to the DPSIR policy cycle.

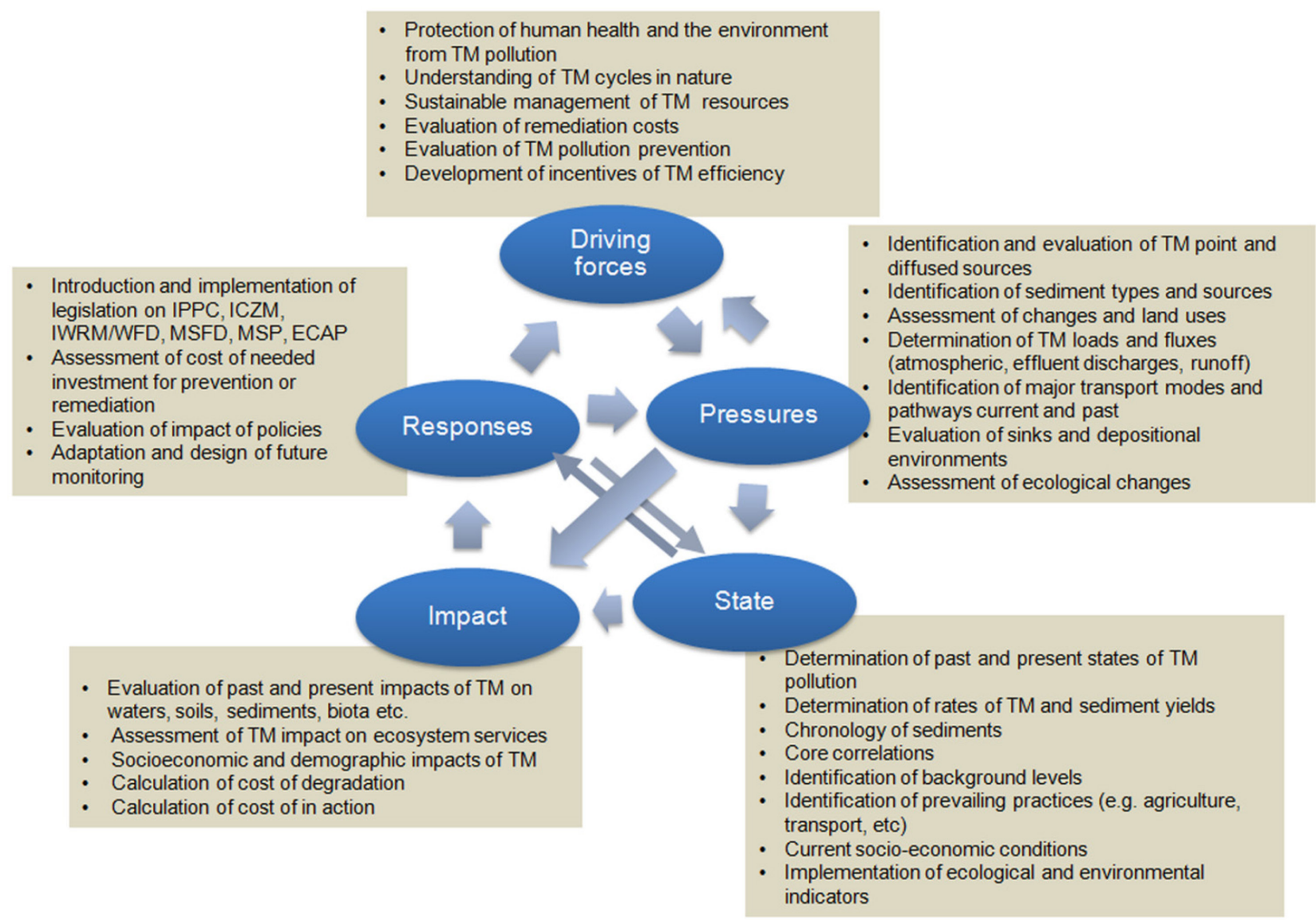




\section{Acknowledgments}

Part of the recent Elefsis research was funded by the "Mediterranean Environment Programme which implements the Capacity Building Component of Horizon 2020 project" (contract No. ENPI/2009/220-191) and will be included in the doctorate thesis of Ioannis Panagiotoulias whom we thank for the valuable unpublished data and information he has kindly provided. We also wish to thank Despoina Kontopoulou for providing laboratory facilities and equipment for carrying out analysis of part of the data set and for reviewing an earlier version of the manuscript. We greatly appreciate the constructive reviews of two reviewers for improving the manuscript. The contribution of Frank Oldfield to the introduction of environmental magnetism in Greek research is greatly acknowledged.

\section{Author Contributions}

Michael Scoullos jointly conceived the structure and wrote the manuscript with Fotini Botsou, collected and analysed data from the Elefsis Gulf, Louros and Acheloos estuaries, with contributions from Frank Oldfield and supervised all studies carried out by the Laboratory of Environmental Chemistry. Fotini Botsou collected and analyzed data from the Elefsis Gulf and the Asopos Estuary. Christina Zeri carried out analysis, interpreted data and wrote the section of the Gulf of Lions.

\section{Conflicts of Interest}

The authors declare no conflict of interest.

\section{References}

1. Salomons, W.; Förstner, U. Metals in the Hydrocycle; Springer-Velag: Berlin, Germany, 1984.

2. Nriagu, J.O.; Pacyna, J.M. Quantitative assessment of worldwide contamination of air, water and soils by trace metals. Nature 1988, 333, 134-139.

3. Fairbrother, A.; Wenstel, R.; Sappington, K.; Wood, W. Framework for metals risk assessment. Ecotoxicol. Environ. Saf. 2007, 68, 145-227.

4. Cave, R.R.; Ledoux, L.; Turner, K.; Jickells, T.; Andrews, J.E.; Davies, H. The Humber catchment and its coastal area: From UK to European perspectives. Sci. Total Environ. 2003, 314-316, 31-52.

5. Chon, H.-S.; Ohandja, D.-G.; Voulvoulis, N. A risk-based approach to prioritise catchments for diffuse metal pollution management. Sci. Total Environ. 2012, 437, 42-52.

6. Scoullos, M.; Oldfield, F.; Thompson, R. Magnetic monitoring of marine particulate pollution in the Elefsis Gulf, Greece. Mar. Pollut. Bull. 1979, 10, 287-291.

7. Berry, A.; Plater, A.J. Rates of tidal sedimentation from records of industrial pollution and environmental magnetism: The Tees Estuary, North-East England. Water Air Soil Pollut. 1998, 106, 463-479.

8. Blundell, A.; Hannam, J.A.; Dearing, J.A.; Boyle, J.F. Detecting atmospheric pollution in surface soils using magnetic measurements: A reappraisal using an England and Wales database. Environ. Pollut. 2009, 157, 2878-2890. 
9. Georgeaud, V.M.; Rochette, P.; Ambrosi, J.P.; Vandamme, D.; Williamson, D. Relationship between heavy metals and magnetic properties in a large polluted catchment: The Etang de Berre (south of France). Phys. Chem. Earth 1997, 22, 211-214.

10. Lecoanet, H.; Lévêque, F.; Ambrosi, J.-P. Magnetic properties of salt-marsh soils contaminated by iron industry emissions (southeast France). J. Appl. Geophys. 2001, 48, 67-81.

11. Robertson, D.J.; Taylor, K.G.; Hoon, S.R. Geochemical and mineral magnetic characterisation of urban sediment particulates, Manchester, UK. Appl. Geochem. 2003, 18, $269-282$.

12. Strzyszcz, Z.; Magiera, T.; Heller, F. The influence of industrial immissions on the magnetic susceptibility of soils in upper Silesia. Stud. Geophys. Geod. 1996, 40, 276-286.

13. Zhang, C.; Qiao, Q.; Piper, J.D.A.; Huang, B. Assessment of heavy metal pollution from a fe-smelting plant in urban river sediments using environmental magnetic and geochemical methods. Environ. Pollut. 2011, 159, 3057-3070.

14. Neal, C.; Leeks, G.J.L.; Millward, G.E.; Harris, J.R.W.; Huthnance, J.M.; Rees, J.G. Land-ocean interaction: Processes, functioning and environmental management from a UK perspective: An introduction. Sci. Total Environ. 2003, 314-316, 3-11.

15. Evans, M.; Heller, F. Environmental Magnetism. Principles and Applications of Enviromagnetics; Academic Press: Waltham, MA, USA, 2003.

16. Liu, Q.; Roberts, A.P.; Larrasoaña, J.C.; Banerjee, S.K.; Guyodo, Y.; Tauxe, L.; Oldfield, F. Environmental magnetism: Principles and applications. Rev. Geophys. 2012, 50, doi:10.1029/2012RG000393.

17. Thompson, R.; Oldfield, F. Environmental Magnetism; Allen and Unwin: London, UK, 1986.

18. Verosub, K.L.; Roberts, A.P. Environmental magnetism: Past, present, and future. J. Geophys. Res. Solid Earth 1995, 100, 2175-2192.

19. Petrovský, E.; Kapička, A.; Jordanova, N.; Knab, M.; Hoffmann, V. Low-field magnetic susceptibility: A proxy method of estimating increased pollution of different environmental systems. Environ. Geol. 2000, 39, 312-318.

20. Scholger, R. Heavy metal pollution monitoring by magnetic susceptibility measurements applied to sediments of the river Mur (Styria, Austria). Eur. J. Environ. Eng. Geophys. 1998, 3, 25-37.

21. Horowitz, A.J.; Elrick, K.A. The relation of stream sediment surface area, grain size and composition to trace element chemistry. Appl. Geochem. 1987, 2, 437-451.

22. Warren, L.A.; Haack, E.A. Biogeochemical controls on metal behaviour in freshwater environments. Earth Sci. Rev. 2001, 54, 261-320.

23. European Environmental Agency (EEA). Environmental Indicators: Typology and Overview; Technical Report No. 25; European Environmental Agency: Copenhagen, Denmark, 1999.

24. Dassenakis, M.; Scoullos, M.; Gaitis, A. Trace metals transport and behaviour in the Mediterranean estuary of Acheloos River. Mar. Pollut. Bull. 1997, 34, 103-111.

25. Scoullos, M.; Dassenakis, M.; Zeri, C. Trace metal behaviour during summer in a stratified Mediterranean system: The Louros Estuary (Greece). Water Air Soil Pollut. 1996, 88, 269-295.

26. Mackereth, F.J.H. A short core sampler for subaqueous deposits. Limnol. Oceanogr. 1969, 14, $145-151$.

27. Agemian, H.; Chau, A.S.Y. Evaluation of extraction techniques for the determination of metals in aquatic sediments. Analyst 1976, 101, 761-767. 
28. Scoullos, M. Chemical Studies of the Gulf of Elefsis, Greece. Ph.D. Thesis, University of Liverpool, Liverpool, UK, 1979.

29. Scoullos, M. Zinc in seawater and sediments of the Gulf of Elefsis, Greece. Water Air Soil Pollut. 1981, 16, 187-207.

30. Scoullos, M.J. Lead in coastal sediments: The case of the Elefsis Gulf, Greece. Sci. Total Environ. 1986, 49, 199-219.

31. Rauret, G.; Lopez-Sanchez, J.F.; Sahuquillo, A.; Rubio, R.; Davidson, C.; Ure, A.; Quevauviller, Ph. Improvement of the $\mathrm{BCR}$ three step sequential extraction procedure prior to the certification of new sediment and soil reference materials. J. Environ. Monit. 1999, 1, 57-61.

32. Botsou, F.; Karageorgis, A.P.; Dassenakis, E.; Scoullos, M. Assessment of heavy metal contamination and mineral magnetic characterization of the Asopos River sediments (Central Greece). Mar. Pollut. Bull. 2011, 62, 547-563.

33. Kersten, M.; Smedes, F. Normalization procedures for sediment contaminants in spatial and temporal trend monitoring. J. Environ. Monit. 2002, 4, 109-115.

34. Dekkers, M.J. Environmental magnetism: An introduction. Geol. Mijnb. 1997, 76, 163-182.

35. Robinson, S.G. Early diagenesis in an organic-rich turbidite and pelagic clay sequence from the Cape Verde Abyssal Plain, NE Atlantic: Magnetic and geochemical signals. Sediment. Geol. 2001, 143, 91-123.

36. Maher, B.A. Characterisation of soils by mineral magnetic measurements. Phys. Earth Planet. Inter. 1986, 42, 76-92.

37. Stober, J.C.; Thompson, R. An investigation into the source of magnetic minerals in some Finnish lake sediments. Earth Planet. Sci. Lett. 1979, 45, 464-474.

38. Xie, S.; Dearing, J.A.; Bloemendal, J.; Boyle, J.F. Association between the organic matter content and magnetic properties in street dust, Liverpool, UK. Sci. Total Environ. 1999, 241, 205-214.

39. Liu, Q.; Roberts, A.P.; Torrent, J.; Horng, C.-S.; Larrasoaña, J.C. What do the HIRM and S-ratio really measure in environmental magnetism? Geochem. Geophys. Geosyst. 2007, 8, doi:10.1029/2007GC001717.

40. Hao, Q.; Oldfield, F.; Bloemendal, J.; Guo, Z. The magnetic properties of loess and paleosol samples from the Chinese Loess Plateau spanning the last 22 million years. Palaeogeogr. Palaeoclimatol. Palaeoecol. 2008, 260, 389-404.

41. Hao, Q.; Oldfield, F.; Bloemendal, J.; Torrent, J.; Guo, Z. The record of changing hematite and goethite accumulation over the past $22 \mathrm{Myr}$ on the Chinese Loess Plateau from magnetic measurements and diffuse reflectance spectroscopy. J. Geophys. Res. Solid Earth 2009, 114, doi:10.1029/2009JB006604.

42. Scoullos, M. Trace metals in a landlocked intermittently anoxic basin. In Trace Metals in Sea Water; Wong, C.S., Bouyle, E., Bruland, K.W., Burton, J.D., Goldberg, E.D., Eds.; Plenum Press: New York, NY, USA, 1983; pp. 351-365.

43. Scoullos, M.; Riley, J.P. Water circulation in the Gulf of Elefsis, Greece. Thalass. Jugosl. 1978, 14, 357-370.

44. Scoullos, M.J.; Oldfield, F. Trace metal and magnetic studies of sediments in Greek estuaries and enclosed gulfs. Mar. Chem. 1986, 18, 249-268. 
45. Heller, F.; Strzyszcz, Z.; Magiera, T. Magnetic record of industrial pollution in forest soils of Upper Silesia, Poland. J. Geophys. Res. Solid Earth 1998, 103, 17767-17774.

46. Oldfield, F.; Scoullos, M. Particulate pollution monitoring in the Elefsis Gulf: The role of mineral magnetic studies. Mar. Pollut. Bull. 1984, 15, 229-231.

47. Dearing, J.A.; Dann, R.J.L.; Hay, K.; Lees, J.A.; Loveland, P.J.; Maher, B.A.; O’Grady, K. Frequency-dependent susceptibility measurements of environmental materials. Geophys. J. Int. 1996, 124, 228-240.

48. Mullins, C.E. Magnetic susceptibility of the soil and its significance in soil science-A review. J. Soil Sci. 1977, 28, 223-246.

49. Oldfield, F.; Barnosky, C.; Leopold, E.B.; Smith, J.P. Mineral magnetic studies of lake sediments. Hydrobiologia 1983, 103, 37-44.

50. Oldfield, F.; Maher, B.A.; Donoghue, J.; Pierce, J. Particle size related, mineral magnetic source sediment linkages in the Rhode River catchment, Maryland, USA. J. Geol. Soc. 1985, 142, $1035-1046$.

51. Panagiotoulias, I. Long Term Impact of Iron and Steel Mill Activities on the Marine Environment of the Mediterranean, Based on Measurements in the Gulf of Elefsis. Ph.D. Thesis, University of Athens, Athens, Greece, in preparation.

52. Zhou, Y.; Ning, X.-A.; Liao, X.; Lin, M.; Liu, J.; Wang, J. Characterization and environmental risk assessment of heavy metals found in fly ashes from waste filter bags obtained from a Chinese steel plant. Ecotoxicol. Environ. Saf. 2013, 95, 130-136.

53. Oldfield, F.H.A.; Jones, M.D.H.; Chester, R.; Dearing, J.A.; Olsson, L.; Prospero, J.M. Magnetic differentiation of atmospheric dusts. Nature 1985, 317, 516-518.

54. Nolting, R.F.; Helder, W. Lead and zinc as indicators for atmospheric and riverine particle transport to sediments in the Gulf of Lions. Oceanol. Acta 1991, 14, 358-367.

55. Oldfield, F.; Higgit, S.R.; Maher, B.A.; Appleby, P.G.; Scoullos, M. A new integrative methodology for desertification studies based on magnetic and short-lived radioisotope measurements. In Proceedings of the Information Symposium in the EEC Programme on Climatology, Mytilene, Greece, 15-18 April 1984.

56. Chester, R.; Sharples, E.J.; Sanders, G.; Oldfield, F. The distribution of natural and non-crustal ferrimagnetic minerals in soil-sized particulates from the Mediterranean atmosphere. Water Air Soil Pollut. 1984, 23, 25-35.

57. Zeri, C. Application of the Environmental Magnetic Methodology in Offshore Marine Systems. The Case of NW Mediterranean Sea. Ph.D. Thesis, University of Athens, Athens, Greece, 1995.

58. Heussner, S.; de Madron, X.D.; Calafat, A.; Canals, M.; Carbonne, J.; Delsaut, N.; Saragoni, G. Spatial and temporal variability of downward particle fluxes on a continental slope: Lessons from an 8-yr experiment in the Gulf of Lions (NW Mediterranean). Mar. Geol. 2006, 234, 63-92.

59. Palanques, A.; de Madron, X.D.; Puig, P.; Fabres, J.; Guillén, J.; Calafat, A.; Canals, M.; Heussner, S.; Bonnin, J. Suspended sediment fluxes and transport processes in the Gulf of Lions submarine canyons. The role of storms and dense water cascading. Mar. Geol. 2006, 234, 43-61.

60. Canals, M.; Puig, P.; de Madron, X.D.; Heussner, S.; Palanques, A.; Fabres, J. Flushing submarine canyons. Nature 2006, 444, 354-357. 
61. Zuo, Z.; Eisma, D.; Gieles, R.; Beks, J. Accumulation rates and sediment deposition in the Northwestern Mediterranean. Deep Sea Res. Part II Top. Stud. Oceanogr. 1997, 44, 597-609.

62. Martin, J.-M.; Elbaz-Poulichet, F.; Guieu, C.; Loÿe-Pilot, M.-D.; Han, G. River versus atmospheric input of material to the Mediterranean Sea: An overview. Mar. Chem. 1989, 28, 159-182.

63. Lipiatou, E.; Saliot, A. Fluxes and transport of anthropogenic and natural polycyclic aromatic hydrocarbons in the western Mediterranean Sea. Mar. Chem. 1991, 32, 51-71.

64. Tolosa, I.; Bayona, J.M.; Albaigés, J. Aliphatic and polycyclic aromatic hydrocarbons and sulfur/oxygen derivatives in northwestern Mediterranean sediments: Spatial and temporal variability, fluxes, and budgets. Environ. Sci. Technol. 1996, 30, 2495-2503.

65. Remoudaki, E.; Bergametti, G.; Buat-Ménard, P. Temporal variability of atmospheric lead concentrations and fluxes over the northwestern Mediterranean Sea. J. Geophys. Res. Atmos. 1991, 96, 1043-1055.

66. Loÿe-Pilot, M.D.; Martin, J.M. Saharan dust input to the western Mediterranean: An eleven years record in Corsica. In The Impact of Desert Dust across the Mediterranean; Guerzoni, S., Chester, R., Eds.; Springer: Berlin, Germany, 1996; Volume 11, pp. 191-199.

67. Scoullos, M.; Zeri, C. The use of mineral magnetic measurements for the study of transport and sedimentation of particles in the Gulf of Lions (N.W. Mediterranean). Oceanol. Acta 1993, 16, $53-61$.

68. Skoulikidis, N. Hydrochemical character and spatiotemporal variations in a heavily modified river of western Greece. Environ. Geol. 2003, 43, 814-824.

69. Skoulikidis, N.T. The environmental state of rivers in the Balkans-A review within the DPSIR framework. Sci. Total Environ. 2009, 407, 2501-2516.

70. Scoullos, M.; Dassenakis, M.; Gaitis, A. Distribution of nutrients in the Acheloos River mouth, Greece. Rapp. Comm. Int. Mer. Med. 1992, 33, 182.

71. Dassenakis, M.; Degaita, A.; Scoullos, M. Trace metals in sediments of a Mediterranean estuary affected by human activities (Acheloos river estuary, Greece). Sci. Total Environ. 1995, 168, $19-31$.

72. Guieu, C.; Martin, J.M. The level and fate of metals in the Danube River Plume. Estuar. Coast. Shelf Sci. 2002, 54, 501-512.

73. Rondeau, B.; Cossa, D.; Gagnon, P.; Pham, T.T.; Surette, C. Hydrological and biogeochemical dynamics of the minor and trace elements in the St. Lawrence River. Appl. Geochem. 2005, 20, 1391-1408.

74. Zhou, J.L.; Liu, Y.P.; Abrahams, P.W. Trace metal behaviour in the Conwy estuary, North Wales. Chemosphere 2003, 51, 429-440.

75. Zwolsman, J.J.G.; van Eck, B.T.M.; van der Weijden, C.H. Geochemistry of dissolved trace metals (cadmium, copper, zinc) in the Scheldt Estuary, Southwestern Netherlands: Impact of seasonal variability. Geochim. Cosmochim. Acta 1997, 61, 1635-1652.

76. Maher, B.A. Magnetic properties of modern soils and Quaternary loessic paleosols: Paleoclimatic implications. Palaeogeogr. Palaeoclimatol. Palaeoecol. 1998, 137, 25-54.

77. Maher, B.A.; Hallam, D.F. Magnetic carriers and remanence mechanisms in magnetite-poor sediments of Pleistocene age, southern North Sea margin. J. Quat. Sci. 2005, 20, 79-94. 
78. Lepland, A.; Stevens, R.L. Mineral magnetic and textural interpretations of sedimentation in the Skagerrak, Eastern North Sea. Mar. Geol. 1996, 135, 51-64.

79. Oldfield, F.; Asioli, A.; Accorsi, C.A.; Mercuri, A.M.; Juggins, S.; Langone, L.; Rolph, T.; Trincardi, F.; Wolff, G.; Gibbs, Z.; et al. A high resolution late Holocene palaeo environmental record from the central Adriatic Sea. Quat. Sci. Rev. 2003, 22, 319-342.

80. Botsou, F. Study on the Impact of Ephemeral Rivers to the Coastal Marine Environment: The Case of the Asopos River, Central Greece. Ph.D. Thesis, University of Athens, Athens, Greece, 2007.

(C) 2014 by the authors; license MDPI, Basel, Switzerland. This article is an open access article distributed under the terms and conditions of the Creative Commons Attribution license (http://creativecommons.org/licenses/by/3.0/). 